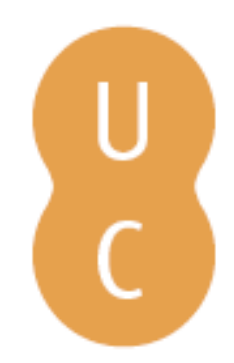

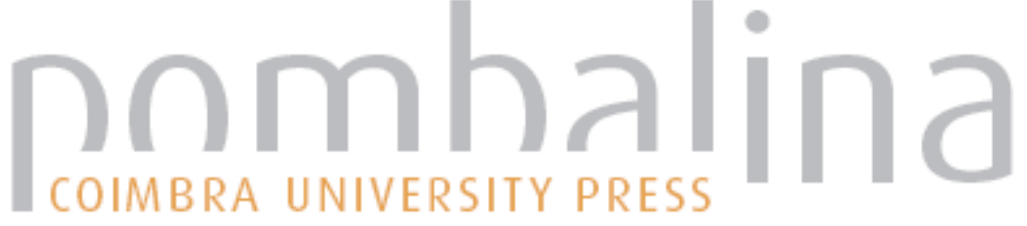

\section{A Faculdade de Matemática (1772-1911)}

Autor(es): $\quad$ Silva, Jaime Carvalho e

Publicado por: Imprensa da Universidade de Coimbra

URL

persistente: URI:http://hdl.handle.net/10316.2/38512

DOI: $\quad$ DOI:http://dx.doi.org/10.14195/978-989-26-0610-1_1

Accessed : $\quad$ 26-Apr-2023 14:47:37

A navegação consulta e descarregamento dos títulos inseridos nas Bibliotecas Digitais UC Digitalis, UC Pombalina e UC Impactum, pressupõem a aceitação plena e sem reservas dos Termos e Condições de Uso destas Bibliotecas Digitais, disponíveis em https://digitalis.uc.pt/pt-pt/termos.

Conforme exposto nos referidos Termos e Condições de Uso, o descarregamento de títulos de acesso restrito requer uma licença válida de autorização devendo o utilizador aceder ao(s) documento(s) a partir de um endereço de IP da instituição detentora da supramencionada licença.

Ao utilizador é apenas permitido o descarregamento para uso pessoal, pelo que o emprego do(s) título(s) descarregado(s) para outro fim, designadamente comercial, carece de autorização do respetivo autor ou editor da obra.

Na medida em que todas as obras da UC Digitalis se encontram protegidas pelo Código do Direito de Autor e Direitos Conexos e demais legislação aplicável, toda a cópia, parcial ou total, deste documento, nos casos em que é legalmente admitida, deverá conter ou fazer-se acompanhar por este aviso.

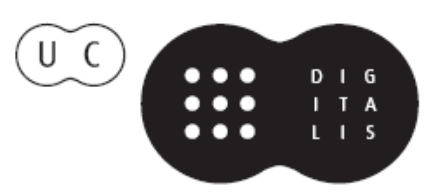



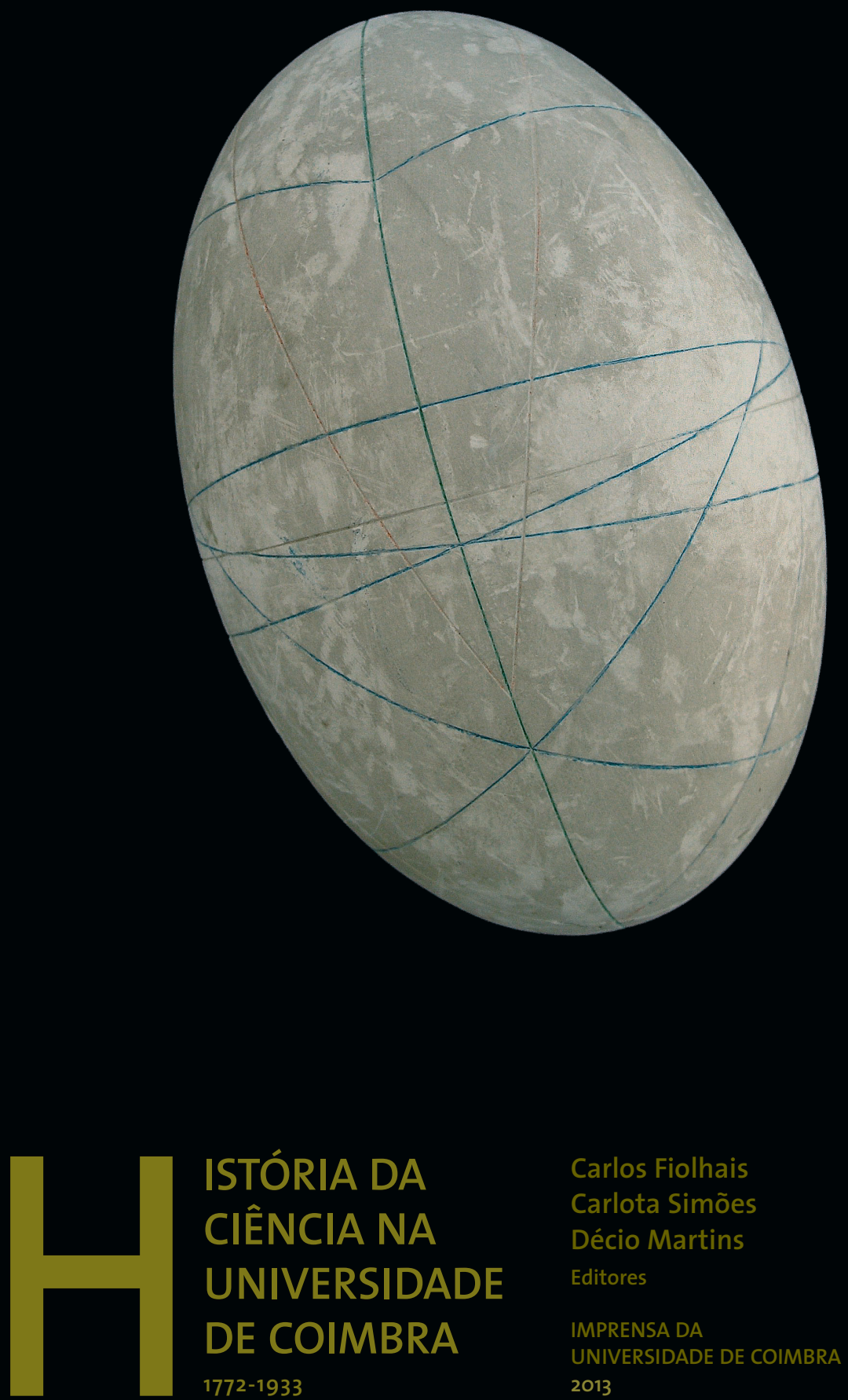

ISTÓRIA DA

CIÊNCIA NA

UNIVERSIDADE

DE COIMBRA

1772-1933
Carlos Fiolhais

Carlota Simões

Décio Martins

Editores

IMPRENSA DA

UNIVERSIDADE DE COIMBRA

2013 
CMUC - Centro de Matemática da Universidade de Coimbra.

A Faculdade de Matemática (1772-1911)

Jaime Carvalho e Silva

\section{INTRODUÇÃO}

A Reforma Pombalina representa um acontecimento sem precedentes para a Matemática em Portugal, com a criação da Faculdade de Matemática a que se atribui um lugar de destaque, sendo considerada nos Estatutos de 1772 "huma Faculdade Maior do Ensino público, incorporada na Universidade, como qualquer das outras Faculdades, que até agora se distinguíram com o nome de Maiores" ${ }^{1}$ sendo mesmo expressamente afirmado que "terá a mesma Graduação, Predicamento, Honras e Privilegios, de que por Direito, e costume gozam as mesmas Faculdades, sem já mais poder haver-se por inferior a ellas por qualquer titulo, ou pretexto, que se possa allegar" ${ }^{2}$, e com a criação de um curso de Matemática para que se estabelecesse "a Profissão Mathematica na Universidade de Coimbra"3 e para que "se criem Mathematicos consumados, que possam succeder nas Cadeiras, e ser empregados no serviço da Patria."

Nesse documento, a segunda parte do Livro III, relativa à Matemática, começa com um elogio rasgado: "Têm as Mathematicas uma perfeição tão indisputável entre todos os conhecimentos naturais, assim na exactidão luminosa do seu Método, como na sublime e admiravel especulação das suas doutrinas, que Ellas não somente e em rigor, ou com propriedade merecem o nome de Sciencias, mas também são as que tem acreditado singularmente a força, o engenho, e a sagacidade do Homem." E mais adiante indica que "se a mesma Universidade ficasse destituída das luzes Mathematicas (...) não seria mais do que hum cháos, semelhante ao Universo, se fosse privado dos resplandores do Sol". Nos Estatutos são mesmo indicadas penas para quem diminuir a importância dos estudos matemáticos: “Todos aquelles, que directa ou indirectamente apartarem ou dissuadirem a alguem dos estudos mathematicos; (...) não serão por mim attendidos em opposição alguma, que façam às cadeiras das suas respectivas Faculdades." Eram também concedidos privilégios para quem frequentasse a Faculdade com aproveitamento ou distinção: "Haverei a todos os Fidalgos da minha Casa por serviço vivo na Campanha, todo o tempo, que cursarem a Mathematica na Universidade" ${ }^{4}$, eram dispensados de todos ou duma parte dos exames na admissão a

\footnotetext{
${ }^{1}$ Estatutos (1772), liv. III, Parte II, tít. I, Cap. II, $₫ 1$.

${ }^{2}$ Ibidem.

${ }^{3}$ Estatutos (1772), liv. III, Parte II, tít. I, Cap. I, $\$ 4$.

${ }^{4}$ Ibidem, Cap. II, $\$ 9$.
} 
profissões militares, e ainda a criação de 18 partidos "perpetuamente" (que existiam apenas para a Faculdade de Medicina) porque o "premio he estímulo eficaz para incitar, e promover a diligencia"5 por se entender que "as Sciencias Mathematicas involvem difficuldades que se não podem vencer sem grande constancia no estudo"6.

No relatório que elaborou em 1777, "Relação Geral do Estado da Universidade", D. Francisco de Lemos analisou os problemas dos primeiros anos de funcionamento da nova Faculdade de Matemática. O principal problema que apontou foi o da baixa frequência: no primeiro ano inscreveram-se 8 estudantes mas um morreu e 2 "desertaram", no $2 .^{\circ}$ ano inscreveram-se 2 mas um "faltou" e nos anos seguintes até 1777 não se inscreveu mais nenhum. E aponta várias medidas para se remediar esta situação "do qual depende em grande parte a felicidade da Monarchia". A causa principal desta situação é, de acordo com o Reitor Reformador da Universidade de Coimbra, "não serem destinados por Ordens Regias os Mathematicos Graduados para os Empregos, e Lugares, que há proprios desta Profissão"7. Por isso D. Francisco de Lemos solicita à Rainha D. Maria II que confirme duas determinações do Rei D. José I que nunca chegaram a ser executadas:

“1. ${ }^{\circ}$ Que os Lugares de Cosmographo Mor, Engenheiro Mor do Reyno, fossem só occupados pelos Mathematicos Graduados.

2. ${ }^{\circ}$ Que em cada huma das Comarcas se creasse um Lugar de Cosmographo Menor para ser occupado pelos mesmos Mathematicos Graduados.

3. ${ }^{\circ}$ Que na cidade do Porto se instituisse huma Cadeira de Astronomia Nautica, para ser tambem regida por um Mathematico Graduado."

D. Francisco de Lemos defende vigorosamente estas medidas, dizendo, por exemplo, da segunda que "faria certamente cessar a metade das Demandas, e huma terça parte dos Crimes nestes Reynos; porque he certo, que muitos crimes se commettem por teimas, e dividas sobre as Propriedades"'.

Mas no mesmo documento são propostas ainda outras medidas que criem mais empregos para "Mathematicos Graduados". Além da cadeira de Náutica no Porto são também propostas iguais cadeiras em Lisboa, Baía e Rio de Janeiro. É indicado o que poderia ser um programa dessa cadeira, a ser frequentada por todos os cadetes da Marinha durante três anos. Propóe que os titulares das cadeiras de Artilharia e Engenharia Militar só fossem ocupadas por "Mathematicos Graduados". E propõe que sejam criadas cadeiras de Geometria em todos os lugares onde se ensinar Filosofia Racional.

Este problema mantém-se com alguma acuidade durante muitos anos, e o número de alunos no curso de matemático foi bastante reduzido até meados do século XIX. Em reunião da Congregação de Matemática de 22 de Maio de 1807, o Reitor, D. Francisco de Lemos, chama a atenção para a "ademinuiçaó progressiva q. se via aresp. ${ }^{\text {to }}$

\footnotetext{
${ }^{5}$ Ibidem, tít. VII, Cap. II, $\$ 1$.

${ }^{6}$ Ibidem.

${ }^{7}$ LEMOS, Francisco de, Relação Geral do Estado da Universidade (1777), Coimbra, 1980, pp. 87-88.

${ }^{8}$ Idibem, p. 89.

${ }^{9}$ Ibidem, p. 90.
} 
do numero d'Estudantes Ordinarios q. sepropuzesem à Formatura de Mathematica"10. Aponta como razão a falta de empregos para matematicos em serviços publicos, e a Congregação roga-lhe que solicite ao Governo a criação de tais empregos.

$\mathrm{Na}$ reforma de 1836 foi determinado que o curso de Matemática seria habilitação suficiente para "os cargos e officios em que for requerida a carta de ingenheiro civil ou militar, assim como para os postos das differentes armas do exercito e da armada, e bem assim para todos os officios ou empregos de Fazenda; devendo ser, em egualdade de circunstancias, preferidos aquelles que junctarem carta de formatura nesta sciencia" ${ }^{11}$. Esta determinação deve ter tido um efeito diminuto conforme se pode ajuizar por uma passagem da Oração de Sapiência proferida pelo Lente da Faculdade de Matemática Luís da Costa e Almeida em 1889: "Poucas, pouquissimas são as profissōes, para cujo exercicio se exige a formatura na faculdade de mathematica"12.

Apesar disso encontramos referências neste período a algumas posições importantes ocupadas por "Mathematicos Graduados": Filipe Folque, doutor em Matemática, é o director geral dos trabalhos geodésicos do Reino, e Francisco António Brito Limpo, bacharel formado em Matemática, é membro da comissão dos trabalhos geodésicos do Reino.

\section{As Cadeiras}

Em 1772, o curso de Matemática foi criado com quatro cadeiras próprias ${ }^{13}$ :

\section{Primeiro Anno}

$1 .^{\text {a }}$ Cadeira

Geometria, comprehendendo Elementos de Arithmetica, Geometria e de Trigonometria Plana, com applicação á Geometria e Stereometria.

Segundo Anno

2. ${ }^{\text {C Cadeira }}$

Algebra, comprehendendo a Algebra elementar, Principios de calculo infinitesimal, directo $e$ inverso, com applicações á Geometria sublime e transcendente.

Terceiro Anno

3. ${ }^{\text {C Cadeira }}$

Phoronomia (Física-Matemática), comprehendendo a sciencia geral do movimento com a sua applicação a todos os ramos de Phoronomia, que constituem o corpo das Sciencias physico-mathematicas.

\section{Quarto Anno}

4. ${ }^{\text {a }}$ Cadeira

Astronomia, comprehendendo a theoria geral do movimento dos astros, tanto physica como geometrica, e a práctica do calculo e observações astronomicas.

\footnotetext{
${ }^{10}$ Actas das Congregaçōes da Faculdade de Matemática (1772-1820), Universidade de Coimbra, 1983, vol. II, p. 94.

${ }^{11}$ FREIRE, Francisco de Castro, Memoria Historica da Faculdade de Mathematica, Coimbra, 1872, p. 65.

${ }^{12}$ Annuario da Universidade de Coimbra - Anno lectivo de 1898-1899, Coimbra, 1899, p. XXVII.

${ }^{13}$ Ibidem, p. 25.
} 
Os alunos tinham também de frequentar as cadeiras do $1 .^{\circ}$ e $2 .^{\circ}$ ano do curso de Filosofia Natural e ainda a cadeira de Desenho e Arquitectura que funcionava em anexo à Faculdade de Matemática ${ }^{14}$.

A cadeira de Geometria do $1 .^{\circ}$ ano era obrigatória para todos os outros cursos da Universidade (incluindo Direito e Teologia). Este facto trouxe alguns problemas; por exemplo, em 1787 um Aviso Régio determinava que se fizessem compêndios de Geometria separados para os alunos dos cursos de Teologia e Direito, o que indicia queixas de uma excessiva dificuldade da cadeira de Geometria para estes alunos. Numa carta enviada pelo Rei à Universidade em 1790 determinava-se que os alunos do curso Jurídico não poderiam inscrever-se no primeiro ano sem ter feito Geometria, o que pressupóe uma tentativa de eliminar a cadeira de Geometria do curso de Direito. Nessa mesma carta se indicava que "os Estudantes Ordinarios da Faculd. ${ }^{\text {e }}$ Phylosophica sejaõ obrigados a houvir as liçoẽs do Profesor da Cadeira de Calculo, do m. ${ }^{\text {mo }}$ modo q̃ o saó os Estudantes Medicos" ${ }^{15}$ o que mais uma vez dá a entender que teria existido um pedido para que tal não acontecesse.

Por Carta Régia de 1 de Abril de 1801 foram criadas 2 cadeiras novas na Faculdade de Matemática, Hidráulica e Astronomia Prática. A cadeira existente de Astronomia passou a ter como tema a Mecânica Celeste. Em 1836 o curso foi totalmente reformado, tendo aumentado para cinco anos, com a criação de uma cadeira de "Architectura civil, militar e subterranea, e artilheria" 16 no $5 .^{\circ}$ ano e a reorganização das cadeiras do $3 .^{\circ}, 4 .^{\circ}$ e $5 .^{\circ}$ anos. A Faculdade de Matemática levantou objecções a esta reforma por considerar que a nova cadeira de Arquitectura tinha um programa impossível de cumprir num ano e que de qualquer modo deveria ser ensinada em escolas próprias. Apresentou assim uma outra proposta de reforma, tendo o Governo implicitamente sancionado a modificação pelo que o novo plano de estudos passou a ser:

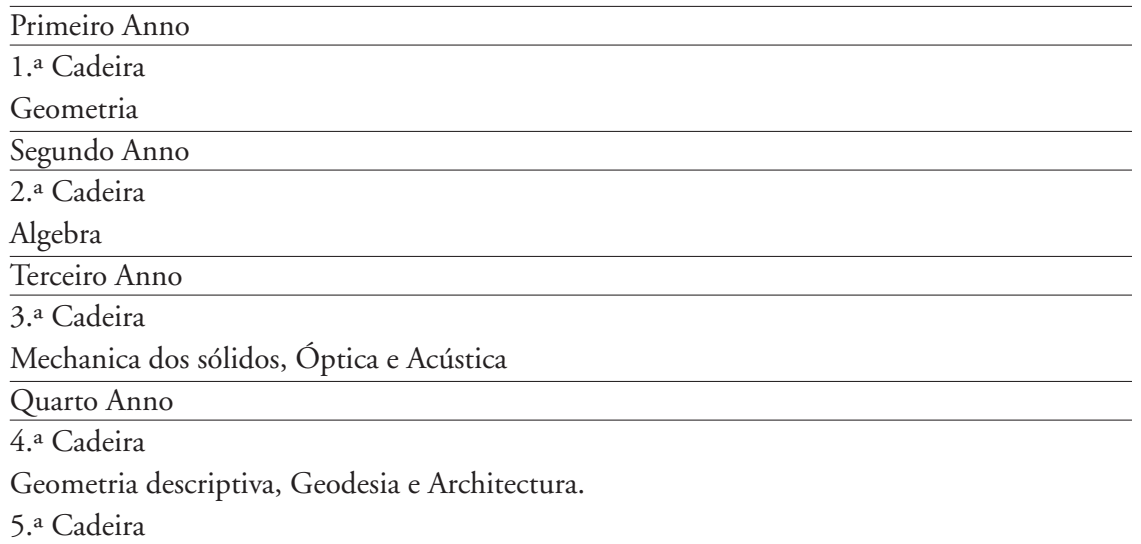

${ }^{14}$ Com um professor subordinado à Congregação da Faculdade de Matemática. Durante muito tempo o Lente da cadeira de Desenho não foi provido por falta de pessoa qualificada. Apenas começou a funcionar depois de 1840 com professores nomeados interinamente e apenas teve um professor proprietário a partir de 1872 . p. 83 .

${ }^{15}$ Actas das Congregaçōes da Faculdade de Matemática (1772-1820), Universidade de Coimbra, 1982, vol. I,

${ }^{16}$ FREIRE, Francisco de Castro, Memoria Historica da Faculdade de Mathematica, Coimbra, 1872, p. 65. 
Astronomia practica

Quinto Anno

6. ${ }^{\text {a Cadeira }}$

Mechanica Celeste

7. ${ }^{\text {a }}$ Cadeira

Hydraulica

Em 1844 foi decretada nova reforma, depois de uma consulta à Faculdade de Matemática, em que esta se dividiu entre os que defendiam um desenvolvimento da Matemática Aplicada e os que defendiam que "nella os estudos theoricos transcendentes tenham o maximo desenvolvimento" ${ }^{17}$. De algum modo acabou por vencer esta última posição pois as três primeiras cadeiras foram reformuladas, aparecendo Cálculo Integral, Cálculo das Variações e, de forma explícita, o estudo das equações diferenciais, na $3 .^{\mathrm{a}}$ Cadeira; para isso esta ficou dividida em duas partes tendo-se mantido a Mecânica na segunda parte, e tendo passado os temas de Acústica e Óptica para as cadeiras do $4 .^{\circ}$ e 5. ${ }^{\circ}$ anos; estes anos, fora esta alteração, ficaram essencialmente na mesma:

\section{Primeiro Anno}

$1 .^{\text {a }}$ Cadeira

Arithmetica; Geometria de Euclides; Algebra até ás equações do 2. ${ }^{\circ}$ gráu inclusivamente; Trigonometria plana.

Segundo Anno

2. ${ }^{\text {a Cadeira }}$

Continuação da Algebra; Algebra Superior; Series - principios elementares de calculo differencial e integral.

\section{Terceiro Anno}

3. ${ }^{\text {a Cadeira }}$

Calculo integral transcendente, de variações, e equações differenciaes até á $3 .^{\mathrm{a}}$ ordem; e na $2 .^{\mathrm{a}}$ parte do anno Mechanica dos solidos.

Em 1855 foi aprovada nova reforma, desta vez por iniciativa da Faculdade de Matemática, tendo desaparecido a referência às Equações Diferenciais e tendo a ligação óbvia entre as Equações Diferenciais e a Mecânica sido substituída por um casamento claramente de conveniência com a Geometria Descritiva. A Hidrostática e a Acústica desapareceram, tendo aparecido a Mecânica dos Fluidos e a Mecânica Aplicada. Os três últimos anos ficaram organizados da seguinte forma:

Terceiro Anno

3. ${ }^{\text {a Cadeira }}$

Calculo superior, differenças finitas; Geometria descriptiva.

4. ${ }^{\text {a }}$ Cadeira

Mechanica racional dos sólidos e fluidos; Óptica.

Quarto Anno

5. ${ }^{\text {a }}$ Cadeira

Astronomia practica

${ }^{17}$ Ibidem, p. 66. 
6. ${ }^{\text {a }}$ Cadeira

Mechanica applicada; Geodesia.

Quinto Anno

7. ${ }^{\text {a }}$ Cadeira

Mechanica Celeste

Contudo, logo em 1857, a Congregação da Faculdade de Matemática propôs a criação de uma nova cadeira de Geometria Descritiva, Acústica e Óptica. O Governo concordou em 1861 com a criação de uma 8. ${ }^{a}$ cadeira de Geometria Descritiva e sugeriu uma redistribuição das matérias. A proposta da Faculdade de Matemática não foi aceite pelo Governo que determinou que se aplicasse uma outra que a Faculdade de Matemática não pôs logo em aplicação por considerar que era impossível de pôr em prática. Essa redistribuição governamental concentrava as três primeiras cadeiras em apenas duas com o desaparecimento da Geometria e Trigonometria elementares e o aparecimento no $2 .^{\circ}$ ano do Cálculo das Probabilidades. O curso ficava com uma feição claramente mais aplicada, visto que até o número de disciplinas obrigatórias a fazer na Faculdade de Filosofia passava de três para cinco cadeiras. A Faculdade de Matemática tentou remediar as dificuldades de tal plano de estudos criando uma introdução na $1 .{ }^{a}$ cadeira que ensinasse as noções elementares de aritmética, álgebra e geometria que não faziam parte do ensino secundário e em dar parte do cálculo diferencial e integral na 3 . $^{a}$ cadeira. Por várias razôes tais planos nunca foram concretizados, tendo o plano de estudos ficado como segue até 1902:

\section{Primeiro Anno}

$1 .^{\text {a }}$ Cadeira

Algebra Superior - principios de theoria dos numeros - geometria analytica a duas e a tres dimensões - theoria das funcçôes circulares - trigonometria espherica.

Segundo Anno

$2 .^{\text {a }}$ Cadeira

Calculo differencial e integral; das differenças, directo e inverso; das variações e das probabilidades.

Terceiro Anno

3. ${ }^{\text {a }}$ Cadeira

Mechanica racional, e suas applicações ás machinas.

4. ${ }^{\text {a }}$ Cadeira

Geometria descriptiva - applicaçôes á stereometria, á perspectiva e á theoria das sombras.

Quarto Anno

5. ${ }^{\text {a }}$ Cadeira

Descripção e uso dos instrumentos opticos - astronomia practica.

6. ${ }^{\text {a }}$ Cadeira

Geodesia - topographia - operações cadastraes.

Quinto Anno

7. ${ }^{\text {a }}$ Cadeira

Mechanica Celeste.

8. ${ }^{\text {a }}$ Cadeira

Physica Mathematica - applicações de mechanica ás construcções. 
Como corolário lógico da controvérsia anterior, a Faculdade de Matemática propôs a criação de uma disciplina de Analyse Mathematica Superior porque "não podem ser ensinados por falta de tempo, nos dois primeiros annos da faculdade de mathematica, capitulos importantes de analyse matemática superior, indispensáveis para o estudo das doutrinas professadas nas $7 .^{a}$ e $8 .^{a}$ cadeiras da mesma faculdade" ${ }^{18}$. Esta posição é expressamente referida na Portaria governamental de 11 de Novembro de 1898 que autoriza a criação da disciplina; esta aparece referida no anuário de 1898 como tendo sido dada no $4 .^{\circ}$ ano do curso por Gonçalo Xavier de Almeida Garrett que era o Lente da $8 .^{\text {a }}$ cadeira.

Em Dezembro de 1901 foi feita uma reforma geral da Universidade ${ }^{19}$, tendo sido alterados os estatutos. Assim, até 1910, altura em que a Faculdade de Matemática foi extinta e integrada na nova Faculdade de Ciências, vigorou o seguinte plano de estudos (os alunos faziam ainda mais duas cadeiras da Faculdade de Filosofia além de 3 cadeiras de Desenho, tal como no anterior plano):

Primeiro Anno

1. ${ }^{\text {a }}$ Cadeira

Álgebra Superior; geometria analytica a duas e a tres dimensões; trigonometria esphérica.

2. ${ }^{\text {a }}$ Cadeira

Geometria descriptiva.

Segundo Anno

3. ${ }^{\text {a }}$ Cadeira

Cálculo differencial e integral.

Terceiro Anno

4. ${ }^{\text {a }}$ Cadeira

Anályse superior.

5. ${ }^{\text {a }}$ Cadeira

Mechánica racional.

Quarto Anno

6. ${ }^{\text {a }}$ Cadeira

Astronomia.

7. ${ }^{\text {a }}$ Cadeira

Geodesia; cálculo das probabilidades.

Quinto Anno

8. ${ }^{\text {a }}$ Cadeira

Mechánica celeste.

9. ${ }^{\text {a }}$ Cadeira

Physica mathemática.

Este plano de estudos consagra o aparecimento da disciplina de Análise Superior e representa já um avanço notável em relação a planos anteriores aproximando-se muito de um moderno plano de Matemática Aplicada às Ciências da Engenharia. $\mathrm{Na}$ 3. ${ }^{\text {a }}$ cadeira eram estudadas Equaçóes Diferenciais Ordinárias e de Derivadas Parciais.

${ }^{18}$ Annuario da Universidade de Coimbra - Anno lectivo de 1898-1899, Coimbra, 1899, pp. 206-207.

${ }^{19}$ Cf. Annuario da Universidade de Coimbra - Anno lectivo de 1901-1902, Coimbra, 1901, pp. 103-120(III). 
$\mathrm{Na} 4 .^{\mathrm{a}}$ cadeira eram estudadas Funções de Variável Complexa, Equações Diferenciais e Cálculo das Variações. $\mathrm{Na} 5{ }^{\mathrm{a}}$ cadeira estudava-se Cinemática, Estática e Dinâmica do ponto material, dos sistemas materiais e dos corpos sólidos, e Hidrostática. Na 6. ${ }^{\text {a }}$ cadeira era estudado o Cálculo das Probabilidades e a Teoria dos Erros das Observa-

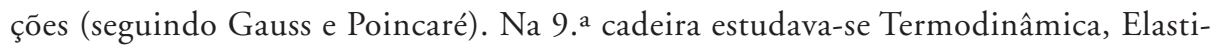
cidade, Teoria Analítica do Calor, Electricidade e Óptica ${ }^{20}$.

\section{Os Professores}

Quando a Faculdade de Matemática foi criada em 1772 não havia doutores em Matemática em Portugal. Assim, para a nova Faculdade são contratados dois professores italianos que já estavam em Portugal no Colégio dos Nobres e dois portugueses: estes, de formação essencialmente autodidacta, merecem menção especial pelos trabalhos originais que produziram: José Monteiro da Rocha e José Anastácio da Cunha.

José Monteiro da Rocha (1734-1819) estudou no Colégio jesuíta da Bahia, Brasil, e foi o principal responsável pela redacção dos Estatutos da nova Faculdade de Matemática. Organizou o Observatório Astronómico da Universidade de Coimbra e traduziu para português livros de Bezout, Bossut e Marie. A sua obra científica centra-se nas áreas de Métodos Numéricos e Astronomia. No trabalho "Additamentos à Regra de M. Fontaine para resolver por aproximação os problemas que se reduzem às Quadraturas”, publicado nas Memórias da Academia das Ciências de Lisboa, apresenta métodos de aceleração da convergência da fórmula de integração aproximada de Fontaine, que, segundo Tiago de Oliveira ${ }^{21}$, é a fórmula extrapolatória de Richardson; esse trabalho ainda apresenta outras fórmulas de majoração do erro da aproximação e trata do caso dos integrais impróprios. Outro trabalho de Análise Numérica diz respeito ao problema da determinação aproximada do volume de um tonel, proposto por Kepler (é o trabalho com que se iniciam as Memórias da Academia das Ciências de Lis$\left.b o a^{22}\right)$. Monteiro da Rocha escreveu vários trabalhos de Astronomia, muitos dos quais foram editados em França com o nome de "Mémoires d'Astronomie Pratique" (Paris, 1808) com tradução de Manuel Pedro de Mello. Um dos mais importantes diz respeito à determinação prática das órbitas parabólicas dos cometas ${ }^{23}$, descoberto antes de Olbers, a quem é atribuído. Outro trabalho, elogiado por Delambre, diz respeito à previsão dos eclipses do Sol. $\mathrm{O}$ método de Monteiro da Rocha para a determinação prática de longitudes, foi analisado e aplicado por Francisco de Paula Travassos, que foi primeiro Lente de Matemática em Coimbra e depois Lente na Academia Real de Marinha.

José Anastácio da Cunha (1744-1787) escreveu um tratado, "Principios Mathematicos”, onde pretendia fornecer bases rigorosas a toda a Matemática da época; aí se

\footnotetext{
${ }^{20}$ Cf. Faculdade de Mathematica - Programmas, Coimbra, 1900.

${ }^{21}$ OLIVEIRA, Tiago de, Obras, vol. II, 1995, p. 142.

${ }^{22}$ Tomo 1 (1787-1788), pp. 1-36, 1797.

${ }^{23}$ Publicado no tomo II das Memórias da Academia das Ciências de Lisboa, 1799, pp. 402-479.
} 
encontra pela primeira vez, com um rigor notável, a definição de série convergente, a definição da função exponencial a partir da sua série de potências, e a de diferencial de uma função. Infelizmente o seu livro, apesar de ter tido duas ediçôes em língua francesa, foi pouco lido e não parece ter influenciado muito o desenvolvimento da matemática. Escreveu ainda um "Ensaio sobre os principios da Mecânica", onde defende uma perspectiva axiomática para a Mecânica, e outras obras que se perderam na sua quase totalidade.

A renovação dos professores da Faculdade de Matemática teria de ser feita com doutoramentos da própria Faculdade. Não foi necessário esperar muito tempo pelos primeiros doutoramentos. Ocorreram em 1777, sete doutoramentos:

\author{
Manuel José Pereira da Silva \\ Manuel Joaquim Coelho da Costa Vasconcellos e Maia \\ Viturio Lopes da Rocha \\ José Simões de Carvalho \\ José Joaquim Victorio \\ Francisco José de Lacerda e Almeida \\ Antonio Pires da Silva Pontes
}

Os três primeiros ficaram Lentes da Faculdade de Matemática. Os dois últimos foram Lentes da Academia Real dos Guardas Marinhas. O doutoramento seguinte, em 1779, foi de Frei Alexandre de Gouveia, protegido de Frei Manuel do Cenáculo, presidente da Junta de Providência Literária. Frei Alexandre de Gouveia foi pouco depois nomeado Bispo de Pequim vindo a pôr em prática os conhecimentos adquiridos ao participar no célebre Tribunal da Matemática de Pequim.

Havendo Doutores em Matemática e tendo alguns dos primeiros Lentes da Faculdade de Matemática sido jubilados ou tendo ido trabalhar para a Corte em Lisboa, a partir de 1777 poderiam ser contratados os primeiros professores formados na própria Faculdade. Por decisão do Conselho de Decanos de 26 de Novembro de 1778 foram nomeados Lentes Substitutos:

Manuel Joaquim Coelho da Costa Maia, para a "Cadeira vaga ${ }^{24}$ de Geometria"

Viturio Lopes da Rocha, para a "Cadeira de Cálculo"

Manuel José Pereira da Silva, para a "Cadeira de Astronomia"

Quando dois dos três novos Lentes deixaram de ser substitutos foi feita uma alteração das cadeiras atribuídas e foi nomeado mais um Lente substituto. Por Carta Régia de 4 de Junho de 1783, confirmada em Conselho de Decanos de 1 de Outubro de 1783, foram nomeados:

José Monteiro da Rocha, Lente da Cadeira de Astronomia

Miguel Franzini, Lente da Cadeira de Phoronomia

Manuel José Pereira da Silva, Lente da Cadeira de Cálculo

Viturio Lopes da Rocha, Lente da Cadeira de Geometria

\footnotetext{
${ }^{24}$ Vaga devido à prisão de José Anastácio da Cunha pela Inquisição em 1777.
} 
e para Lentes substitutos

Manuel Joaquim Coelho da Costa Maia, "substituisse a Cadeira de Phoronomia"25 Francisco Xavier da Veiga ${ }^{26}$, "as cadeiras do segundo e quarto anno.”

Por carta Régia de 12 de Janeiro de 1787, confirmada em Conselho de Decanos de 1 de Fevereiro, José Joaquim de Faria ${ }^{27}$ foi nomeado Lente Substituto Ordinário.

Assim, o quadro de professores foi-se progressivamente regularizando de modo a ficar habilitado com os professores necessários à leccionação das diferentes disciplinas. Tal regularidade só foi interrompida com as invasões napoleónicas e com as atribulações devidas à Guerra Civil. No final da guerra civil em 1834, os Lentes António Honorato de Caria e Moura e Joaquim Lebre de Vasconcelos foram demitidos por razões políticas (mais tarde foram readmitidos mas logo jubilados), outros Lentes foram nomeados para cargos governamentais (Frei Agostinho de Santo Ilídio, Tomás de Aquino e José Ferreira Pestana) ou para outras escolas (Sebastião Corvo de Andrade, Guilherme Dias Pegado e Filipe Folque). O Lente Agostinho Pinto D'Almeida chegou a reger duas cadeiras simultaneamente, e para os exames de 1836 foram nomeados pelo governo dois lentes da Academia de Marinha e depois, juntamente com o único Lente já referido, realizar os exames.

Podemos dizer que no século XIX há vários professores que se distinguem, apesar de a sua obra estar ainda muito pouco estudada. Vamos referir apenas alguns deles.

Manuel Pedro de Mello (1765-1833), aluno de José Anastácio da Cunha, foi o primeiro professor de Hidráulica da Universidade de Coimbra para o que se preparou realizando uma visita de estudo pela Europa; no seu curso seguiu, entre outros, o livro de Mecânica dos Fluidos de Poisson; o trabalho mais importante que escreveu, e que se perdeu, foi a "Memoria sobre o programma da demonstração do parallelogrammo das forças", escrito para um concurso muito concorrido da Academia Real das Ciências de Copenhague em 1806, tendo ganho o respectivo prémio.

Francisco de Paula Travassos (1764-1833) foi Lente substituto da Faculdade de Matemática da Universidade de Coimbra até 1799, data em que publicou o trabalho "Ensaio sobre brachistochronas e reflexôes" ${ }^{2}$. Foi depois Lente da Academia Real de Marinha de Lisboa, tendo publicado vários trabalhos de Astronomia e Geodesia, nomeadamente análises e aplicações de trabalhos de Monteiro da Rocha.

Francisco de Castro Freire publicou obras didácticas e históricas de que a mais conhecida é a "Memoria Historica da Faculdade de Mathematica" que fornece um excelente panorama do desenvolvimento da matemática em Portugal até 1872.

${ }^{25}$ É indicado para a cadeira de "Phoronomia" pois a mesma Acta indica, relativamente a Miguel Franzini, que o Lente permaneceria ausente em Lisboa: "Concervandoce no Real serviço em q. S. ${ }^{a}$ Mag. ${ }^{\text {de }}$ o tem empregado na Corte".

${ }^{26}$ Que se doutorou em 1781.

${ }^{27}$ Que se doutorou em 1782.

${ }^{28}$ Memórias da Academia Real das Ciências, 1.a série, pp. 3-16. 
Rodrigo Ribeiro de Sousa Pinto (1808-1893) foi Director do Observatório Astronómico da Universidade de Coimbra, membro da Academia das Ciências de Lisboa, e publicou inúmeros trabalhos de Astronomia. O mais conhecido, "Cálculo das Ephemerides," de 1849 deu base sólida ao cálculo das efemérides astronómicas tendo feito subir de tal modo o nível das publicações anuais em Coimbra com as efemérides que a Academia das Ciências de Lisboa decidiu deixar de publicar, a partir de 1863, as que editava.

Luis da Costa e Almeida doutorou-se em 1862 com uma tese de equações diferenciais intitulada "Apreciação das hypotheses physicas em que se tem fundado a theoria das refraç̧óes atmosféricas", publicou em 1870 o texto "Exposição succinta dos principios fundamentaes do calculo das variaçôes" (fig. 1), em 1883 o texto "Primeiras noções da theoria dos determinantes" (1883), e publicou artigos sobre equações de derivadas parciais e suas aplicações à mecânica e artigos expositórios. Foi ainda presidente da Câmara de Coimbra, Director da Faculdade de Matemática e membro do Conselho Superior de Instrução Pública.
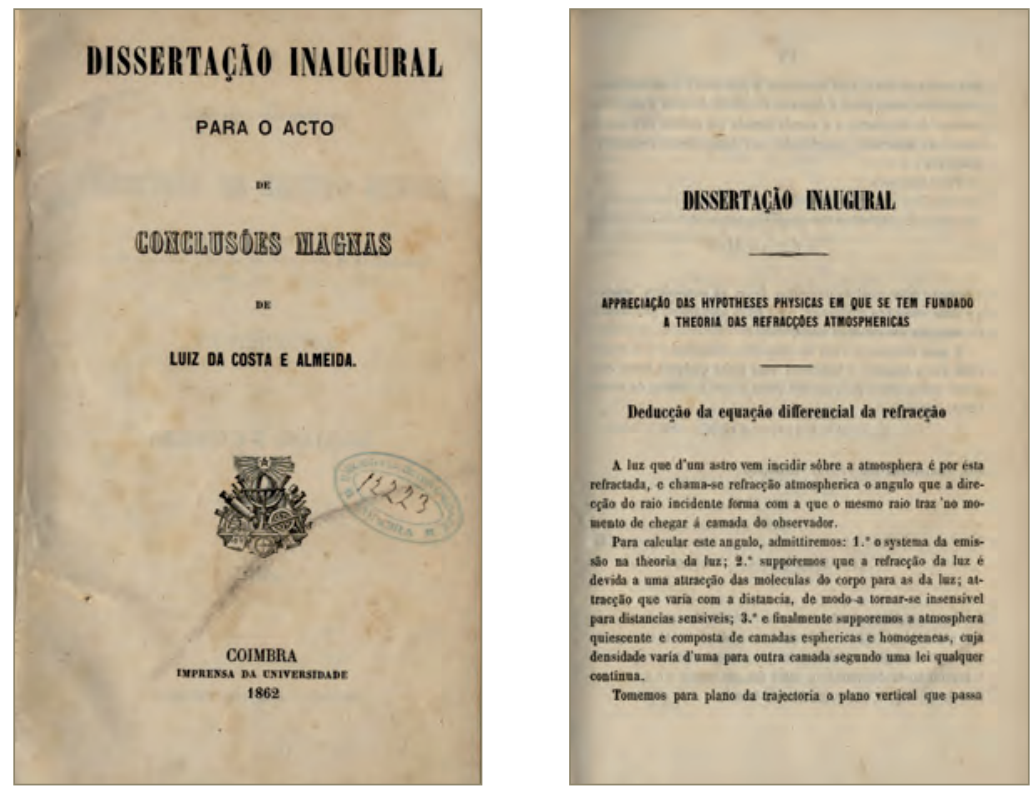

Figura 1 - Dissertação inaugural para o acto de conclusões magnas de Luiz da Costa e Almeida. - Coimbra: Imprensa da Universidade, 1862.

Francisco Gomes Teixeira (1851-1933) doutorou-se em 1875 com uma tese intitulada "Integração das equaçôes de derivadas parciaes de 2. a ordem". Logo como aluno publicou dois trabalhos: "Desenvolvimento das funçôes em fraç̧ôes contínuas" (Coimbra, 1871) e "Aplicação das fracçôes contínuas à determinação das raízes da equaçôes" (no "Jornal de Sciencias Mathematicas, Physicas e Naturaes" da Academia das Ciências de Lisboa, tomo 4, 1872-1873). Foi nomeado Lente substituto da Faculdade de Matemática em 1876 e catedrático em 1879. Fundou em 1877 o "Jornal de 
sciencias mathematicas e astronomicas" que se publicou até 1905 (fig. 2). Em 1883 transferiu-se para a Academia Politécnica do Porto, onde continuou a sua obra notável sendo ainda hoje um dos matemáticos portugueses mais conhecidos no estrangeiro.

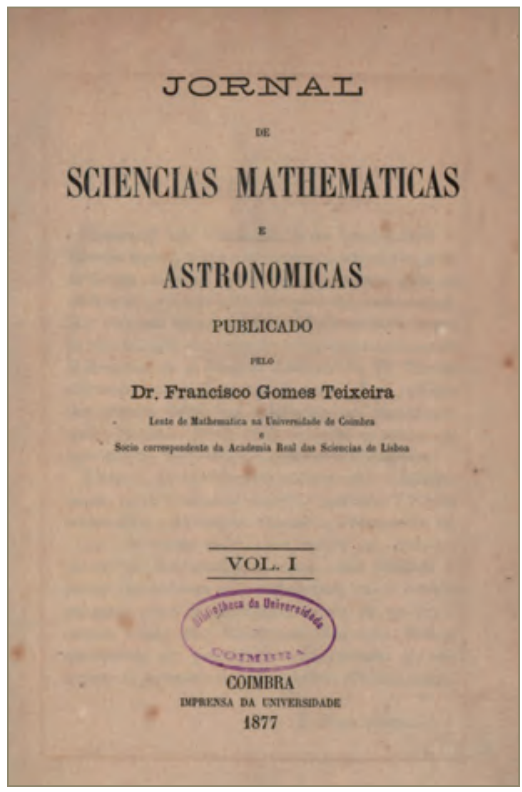

Figura 2 - Jornal de sciencias mathematicas e astronómicas publicado por Francisco Gomes Teixeira.

José BRUno de CABEDo doutorou-se em 1884 com uma tese intitulada "Integração das equações canónicas do movimento" (1884) e a dissertação de concurso para professor em Coimbra foi "Primeiras noçōes sobre a teoria das funç̧ôes uniformes" (1885); publicou oito artigos no Jornal de Sciencias Mathematicas e Astronomicas como "Sobre a formula de Taylor" (1886), "Sobre o resto da formula de Taylor" (1891), "Sobre os coeficientes da serie de Fourier" (1896), e publicou ainda na revista Mathesis (Gand) o artigo "Sur le développement des fonctions en série" (1890).

Luciano Pereira da Silva (1864-1926) doutorou-se em 1889 com uma tese, "Pressóes desenvolvidas no interior de liquidos em movimento", onde estuda trabalhos de Kleitz e Boussinesq (fig. 3). É mais conhecido pela sua vasta obra sobre a História dos Descobrimentos, tendo em particular estudos sobre Pedro Nunes. É menos conhecida a sua actividade de actuário ${ }^{29}$ : foi o responsável pelos primeiros Estatutos aprovados

${ }^{29}$ Deve também se referida neste contexto a carta de Luciano Pereira da Silva (de 1912) reproduzida no n. ${ }^{\circ}$ 26, 1945, da revista "Gazeta de Matemática” sobre o ensino da teoria matemática dos seguros na Alemanha. Aí é referido que Sidónio Pais, enquanto Vice-Reitor, fez uma proposta de criação de um curso de Estatística e de um curso de Matemática dos Seguros, que não foram aprovados. 
oficialmente da companhia Portugal Previdente, e foi um dos autores do trabalho "Bases Técnicas das Companhias portuguezas de seguros de vida" editado em 1909 pela Imprensa da Universidade de Coimbra.

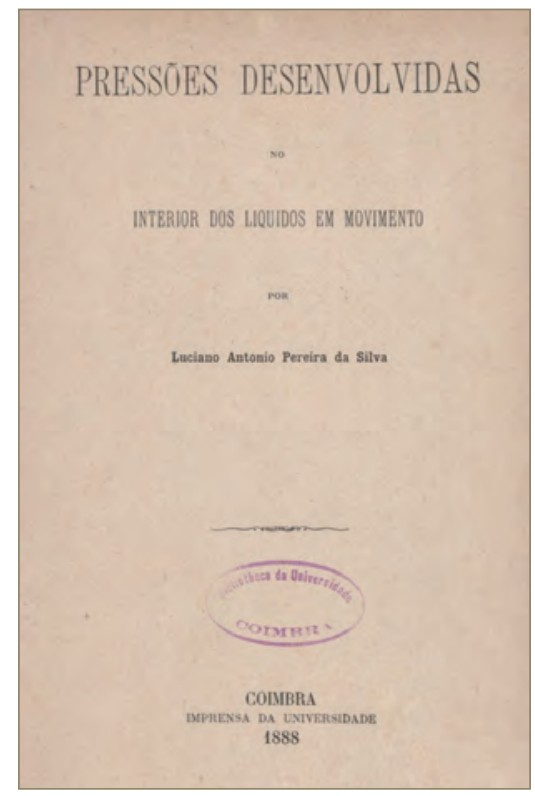

Figura 3 - Pressões desenvolvidas no interior dos líquidos em movimento de Luciano António Pereira da Silva.

Até meados do século XIX, as principais publicações de matemática foram praticamente as das Memórias da Academia das Ciências, onde colaboraram vários Lentes da Faculdade de Matemática. Só a partir de 1857 começaram a ser obrigatoriamente publicadas na Universidade as dissertaçōes de doutoramento. Com a fundação da revista do Instituto de Coimbra, em 1853, começam a aparecer mais trabalhos de Matemática, por uma coincidência curiosa como veremos, mas também devido ao dinamismo da Faculdade de Matemática. Começando com muitas dificuldades económicas, o Instituto de Coimbra solicitou o apoio do governo para a publicação da revista "O Instituto"; este concede-lho mas com a condição de publicar "demonstraçōes, additamentos e memorias, com que os respectivos professores substituissem ou ampliassem alguma parte dos compendios por onde explicam"30. Apenas a Faculdade de Matemática aproveitou a oportunidade tendo no mesmo ano em que foi decidido o apoio do Governo, começado a publicar aí textos, na sua maioria claramente de apoio aos alunos. Muitos desses textos foram depois publicados separadamente e vendidos aos alunos. O número e variedade desses textos são tal que não poderão ser aqui referidos na totalidade. Entendo que merecem um estudo à parte. Referirei apenas aqueles que aparecem nos dez primeiros volumes da revista do Instituto de Coimbra (1853-1862):

${ }^{30}$ In “O Instituto", 1855, vol. III, p. 11. 
Rufino Guerra Osório, Integraes definidos, vol. III, pp. 59-64, pp. 105-108, vol. V, pp. 213-216.

R.R. Sousa Pinto, Apontamentos de Trigonometria Spherica, vol. III, pp. 130-133, pp. 185-188.

Rufino Guerra Osório, Additamento á Geometria de Legendre, vol. III, pp. 234-235 .

R.R. Sousa Pinto, Principio dos limites, e aplicação delle, vol. III, pp. 323-324.

R.R. Sousa Pinto, Apontamentos de Optica, vol. III, pp. 264-267, vol. IV, pp. 25-28, pp. 167-168, pp. 179-180 (e 4 estampas com 21 figuras entre as pp. 176-177).

Rufino Guerra Osório, Appontamentos sobre a theoria das paralelas, vol. IV, pp. 86-88.

Jacome Luiz Sarmento, Methodo facil ... formulas das variações seculares das excentricidades..., vol. VI, p. 121.

António José Teixeira, Triseç̧ão do angulo por meio de hyperbole e circulo, vol. VI, pp. 121-124, pp. 134-136, pp. 177-179, pp. 191-192.

Jacome Luiz Sarmento, Refutação de uma proposição de Du-Bourgeut sobre o calculo integral, vol. VI, p. 121.

Jacome Luiz Sarmento, Discussão do valor da função perturbadora..., vol. VI, pp. 93-96, pp. 107-108.

Jacome Luiz Sarmento, Reflexóes acerca da passagem das equaçóes do movimento elliptico para as dos movimentos hyperbolico e parabolico, vol. VI, pp. 273-276.

Luiz Albano de Andrade Moraes, Eclipses do Sol, vol. VII, pp. 5-6.

R.R. Sousa Pinto, Eclipse do Sol, vol. VII, pp. 22-23.

Jacome Luiz Sarmento, Methodo facil ... distancias lunares..., vol. VII, pp. 94-96. Jacome Luiz Sarmento, Methodo facil ... declinaçóes da lua..., vol. VII, pp. 141-143 .

Jacome Luiz Sarmento, Analyse das demonstraçôes dos theoremas de Laplace...., vol. VIII, pp. 54-55.

Sebastião Corvo D'Andrade, Nota sobre a dizima periodica, vol. VIII, pp. 291-294.

Sebastiāo Corvo D’Andrade, Breves noções do methodo de exaustão, vol. VIII, pp. 299-301.

Jacome Luiz Sarmento, Desenvolvimento de alguns calculos..., vol. VIII, pp. 343-352.

Sebastiāo Corvo D'Andrade, Nota sobre o Livro $V$ de Euclides e particularmente sobre a definição $V$, vol. VIII, pp. 372-376.

Sebastiāo Corvo D'Andrade, Nota sobre as propriedades das linhas trigonometricas, vol. VIII, pp. 377-385.

Francisco Castro Freire, Additamento ano n. 226 dos elementhos de Mechanica Racional dos Solidos, vol. IX, pp. 41-43.

Francisco Torres Coelho, Das involventes, vol. IX, pp. 150-151.

Francisco Torres Coelho, Das funç̧ôes cuja geração é dada pelas series, vol. IX, pp. 213-218.

António José Teixeira, Sobre series exponenciais, vol. IX, pp. 307-308.

António José Teixeira, Sobre series exponenciais e logarithimicas, vol. X, pp. 34-35.

António José Teixeira, Physica-Mathematica, vol. X, pp. 206-210.

J. R. Ramos, Há no pendulo desvios aparentes e reais, vol. X, pp. 78-81, 102-106. 
Este número considerável de 28 textos mostra o dinamismo de dez anos da Faculdade de Matemática, ao se preocupar com a melhoria e actualização de temas contidos nos textos que seguiam nas suas cadeiras, tendo sido continuado em anos posteriores. Uma boa indicação da actualização dos professores da Faculdade de Matemática é dada pelo seguinte extracto da introdução do texto "Physica-Mathematica" de António José Teixeira já citado: "Consultámos algumas memórias, especialmente as das Academias de França, Turim e Berlim, o jornal da Eschola Polytechnica de Paris, e o de Mr. Liouville; os tractados de Cálculo differencial e integral de Lacroix, Cournot, Duhamel, e Timmermans; e a theoria das funcçōes ellipticas de Verhulst".

Apesar deste volume de publicaçōes, a difusão de trabalhos portugueses no estrangeiro era muito deficiente. É bem conhecido o caso de Daniel da Silva. Sousa Pinto ${ }^{31}$ conta o caso de um trabalho de 1799 de Francisco de Paula Travassos sobre o cálculo de certas distâncias que foi mais tarde "redescoberto" por um cientista estrangeiro que o apresentou à Academia das Ciências de Paris em 1857. A propósito, comenta Francisco de Castro Freire: "Este caso, e outros muitos como este, fazem sentir a necessidade urgente de promover por todos os meios o nosso commercio litterario com as corporaçôes scientificas extrangeiras, para que estas dêem o devido apreço a muitas riquezas nossas que lhes são desconhecidas (...) que sabidas nos acreditariam sobremaneira" ${ }^{2}$. E avança com a explicação de a ignorância no estrangeiro do que se fazia em Portugal ser "devida talvez ao pouco conhecimento da nossa lingua" ${ }^{33}$. A promoção do "commercio litterario" só começará a ser feita com a fundação em 1877 do "Jornal de sciencias mathematicas e astronomicas" por Francisco Gomes Teixeira.

Deve ainda ser assinalado o texto de Adriāo Pereira Forjaz de Sampaio, Lente da Faculdade de Direito, "Resumo das preleçôes sobre a theoria da Estadística no curso de 1851-1852 na Universidade" em que relata o que se passou no que deverá ser o primeiro curso de Estatística de uma Universidade portuguesa. Adrião Sampaio é ainda autor do primeiro Curso de Estatística publicado em português "Primeiros Elementos de Ciência Estatística" (Coimbra, 1841). Não se conhece o grau de interacção deste curso com a Faculdade de Matemática. Note-se que Rodolfo Guimarães não considera estes trabalhos na sua compilação.

\section{Os Textos}

Os Estatutos de 1772 determinavam que se editassem livros para cada uma das cadeiras. Foram feitas várias traduçōes, mas só a pouco e pouco foram sendo produzidos alguns originais. As primeiras traduçôes foram feitas por José Monteiro da Rocha. Traduziu os Elementos de Arithmetica de Bezout ${ }^{34}$, os Elementos de Trigonometria Plana

${ }^{31}$ PINTO, R. R. Sousa, Astronomia Náutica, “O Instituto", 1857, vol. V, pp. 10-11.

${ }^{32}$ FREIRE, Francisco de Castro, Memoria Historica da Faculdade de Mathematica, Coimbra, 1872, pp. 49-50.

${ }^{33}$ Ibidem, p. 49.

${ }^{34}$ A 1 .a edição da tradução, com vários aditamentos de Monteiro da Rocha, foi feita em 1773 e a última em 1826. 
de Bezout ${ }^{35}$, o Tractado de Mechanica do Abade Marie ${ }^{36}$ e o Tractado de Hydrodinamica de Bossut ${ }^{37}$. Foram também traduzidos os Elementos de Euclides ${ }^{38}$ e os Elementos de Geometria de Bezout ${ }^{39}$ (fig. 4). A primeira edição da tradução dos Elementos de Analyse de Bezout data de 1774 e foi feita por Fr. Joaquim de Santa Clara, tendo José Joaquim de Faria sido o responsável pela 2. a edição, revista e aumentada, em 1825.

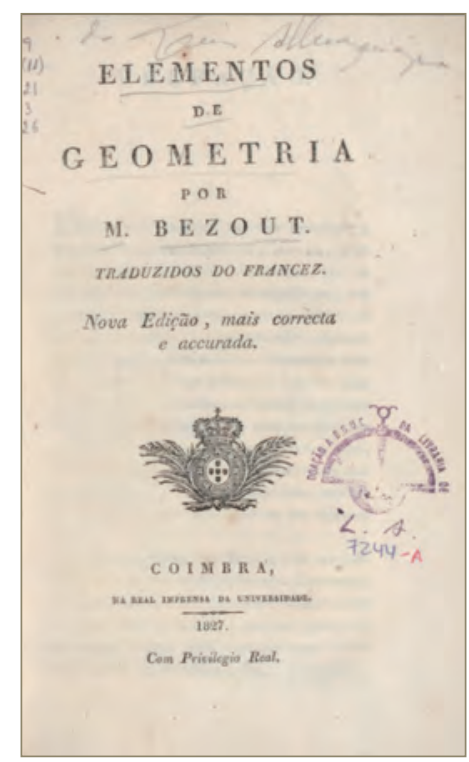

Figura 4 - Elementos de geometria por M. Bezout; traduzidos do francez.

- Nova ed., mais correcta e accurada. - Coimbra: Na Real Imprensa da Universidade, 1827.

No período em referência foram editados os seguintes textos originais de professores da Faculdade de Matemática ${ }^{40}$ :

Monteiro da Rocha, Taboas Astronomicas, Coimbra, 1813.

Sebastiāo Corvo D'Andrade, Nota sobre as propriedades das linhas trigonometricas, Coimbra, 1825.

Sebastiāo Corvo D'Andrade, Nota sobre a dizima periodica com breves noçôes do methodo de exaustão, Coimbra, 1825.

Sebastião Corvo D'Andrade, Nota sobre o Livro $V$ de Euclides e particularmente sobre a definição V, Coimbra, 1825.

\footnotetext{
${ }^{35}$ A $1 .{ }^{a}$ edição da tradução foi feita em 1774 e a última em 1817.

${ }^{36}$ A última edição data de 1812 .

${ }^{37}$ A última edição data de 1813 .

${ }^{38}$ Tradução da versão latina de Frederico Commandino, editada por Roberto Simson. A última edição da tradução data de 1862 .

${ }^{39}$ A última edição data de 1827.

${ }^{40}$ Não se incluem aqui os livros de Desenho.
} 
R. R. Sousa Pinto, Additamento ás notas do calculo differencial e integral de Francoeur, Coimbra, 1845.

R. R. Sousa Pinto, Calculo das ephemerides astronomicas, Coimbra, 1849.

Francisco de Castro Freire, Elementos de mechanica racional dos solidos (2 vol.), Coimbra, 1853.

R. R. Sousa Pinto, Complementos da Geometria Descriptiva de Lefebure de Fourcy, Coimbra, 1853.

R. R. Sousa Pinto, Apontamentos de Trigonometria Spherica, Coimbra, 1854.

R. R. Sousa Pinto, Elementos de Astronomia (2 partes), Coimbra, 1858 (2. ${ }^{\text {a ed. }}$ 1873).

Francisco de Castro Freire, Geometria theorica e applicada, extrahida principalmente das Geometrias de Francoeur e Sonnet, Coimbra, 1859.

R. R. Sousa Pinto, Additamento ao calculo dos eclipses, Coimbra, 1868.

Luiz da Costa e Almeida, Breves apontamentos sobre a natureza, procedencia e signaes das linhas trigonometricas, Coimbra, 1868.

R. R. Sousa Pinto, Nota sobre a parallaxe equatorial do sol, Coimbra, 1869.

Luiz da Costa e Almeida, Theoria dos contactos das superficies e curvas no espaço, e suas principaes applicaçôes, Coimbra, 1869 (2. ${ }^{\text {a }}$ ed. 1885).

Luiz da Costa e Almeida, Exposição succinta dos principios fundamentaes do calculo das variaçôes, Coimbra, 1870.

Luiz da Costa e Almeida, Integração das equaçôes differenciais parciaes, não lineares, de primeira ordem, entre três variaveis, Coimbra, 1873.

Luiz da Costa e Almeida, Dynamica do Ponto Material, Coimbra, 1878 (2. ${ }^{\mathrm{a}}$ ed. 1879, 3. ${ }^{\mathrm{a}}$ ed. 1894).

Luiz da Costa e Almeida, Primeiras noçôes da theoria dos determinantes, Coimbra, 1883.

José Bruno de Cabedo, Theoria dos numeros limites, Coimbra, 1883.

Souto Rodrigues, Additamento á Algebra Superior de Francoeur, Coimbra, 1886.

Luiz da Costa e Almeida, Apontamentos sobre a transformação e integração das equaçôes differenciais da dynamica, Coimbra, 1890.

Souto Rodrigues, Liçôes de Algebra, Coimbra, 1892 (2. ${ }^{\mathrm{a}}$ ed. 1899).

Luiz da Costa e Almeida, Estatica do ponto material e dos sistemas rigidos, Coimbra, 1893.

Souto Rodrigues, Trigonometria Espherica, Coimbra, 1897.

Alguns destes textos eram republicações de textos saídos na revista "O Instituto", como antes foi assinalado, ou foram depois republicados na mesma revista. Esta é assim uma lista de 24 publicações ${ }^{41}$ que, mesmo se algumas apenas têm quatro páginas, não deixa de mostrar mais uma vez a dinâmica dos professores da Faculdade de Matemática.

Antes de se criar esta dinâmica de publicações várias vezes o governo insistiu com a Universidade para que fossem publicados compêndios. Em 1787 um Aviso Régio determinava que se fizessem dois novos compêndios de Geometria, "hum mais rezu-

${ }^{41}$ Provavelmente incompleta pois é bastante difícil identificar dentre as publicações dos professores quais são os textos didacticos universitarios. 
mido, porem que seja bastante, e com bom Methodo, para servir ao ensino das Estudantes das Faculdades Theologica, e Juridicas; e outro mais Largo e amplo, que haja de servir aos Estudantes de Medicina”². Aí se defendia que os Elementos de Euclides só deveriam ser estudados pelos alunos do curso de Matemática, enquanto os estudantes das outras Faculdades apenas precisavam de ficar a saber "a Geometria que lhes baste, e os habilite a racionarem (sic) recta e consequentemente" ${ }^{43}$. Quando os compêndios estivessem prontos se determinaria qual o horário a praticar para os alunos dos diferentes cursos, o que penso nunca veio a concretizar-se. Em Aviso Régio de 11 de Fevereiro de 1790 determina-se que enquanto não existirem os compêndios referidos atrás, os exames de Geometria deveriam fazer-se "sem se exigir dos que se propóem applicar-se a os Estudos Theologicos, Juridicos, ou Medicos, tanto como dos que se dedicarem ás Sciencias Mathematicas" ${ }^{44}$

Em face destas dificuldades, por volta de 1805 deixou de vigorar a obrigação de os alunos destas Faculdades frequentarem o 1. ${ }^{\circ}$ ano da Faculdade de Matemática, passando apenas a ser obrigados a fazer exame de Aritmética e Geometria Elementar antes da matrícula nas respectivas Faculdades.

Francisco de Castro Freire ${ }^{45}$ indica quais os compêndios que a tradição refere como tendo sido adoptados para as diversas cadeiras a partir de 1772:

\begin{tabular}{l} 
Primeiro Anno \\
Elementos de Arithmetica de Bezout, Elementos de Trigonometria Plana de Bezout, Elementos \\
de Euclides \\
\hline Segundo Anno \\
\hline Elementos de Analyse de Bezout \\
Terceiro Anno \\
Tractado de Mechanica do Abade Marie (fig. 5), Tractado de Hydrodinamica de Bossut, Optique \\
de Lacaille \\
Quarto Anno
\end{tabular}

Astronomie de Lalande

Esta lista difere bastante da indicada por D. Francisco de Lemos ${ }^{46}$, mas é provável que a de Francisco de Castro Freire seja a mais exacta pois a lista de D. Francisco de Lemos refere para o primeiro ano apenas os Elementos de Euclides, não indicando nenhum dos compendios de Bezout, que tendo sido traduzidos e sucessivamente reeditados eram certamente também usados nas cadeiras. D. Francisco de Lemos não refere também o livro de Bossut que foi reeditado até 1813 e indica ainda um compêndio não especificado de Lacaille para o quarto ano.

Até 1865 não é fácil saber com exactidão quais os compêndios oficialmente adoptados para as diversas cadeiras. Segundo Francisco de Castro Freire ${ }^{47}$ sabe-se que para

\footnotetext{
${ }^{42}$ In ALMEIDA, M. Lopes d', Documentos da Reforma Pombalina, vol. II, Coimbra, 1979, pp. 128-130.

${ }^{43}$ Ibidem.

${ }^{44}$ Ibidem, pp. 284-285.

${ }^{45}$ FREIRE, Francisco de Castro, Memoria Historica da Faculdade de Mathematica, Coimbra, 1872, p. 50.

${ }^{46}$ LEMOS, Francisco de, Relação Geral do Estado da Universidade (1777), Coimbra, 1980, pp. 82-83.

${ }^{47}$ FREIRE, Francisco de Castro, Memoria Historica da Faculdade de Mathematica, Coimbra, 1872.
} 
a cadeira de Hidráulica, quando foi criada, foram adoptados a Mécanique des Fluides de Poisson e o Traité des torrents et fleuves de Favre. Para a cadeira de Astronomia Prática o compêndio de Astronomia de Lacaile foi substituído pelo de Biot a partir de 1821. Na cadeira de Mecânica Celeste era estudado o texto de Mecânica Celeste de Laplace, o que, segundo Castro Freire obrigava os alunos a estudar teorias avançadas de análise e mecânica por outros trabalhos e artigos de revistas científicas ${ }^{48}$.

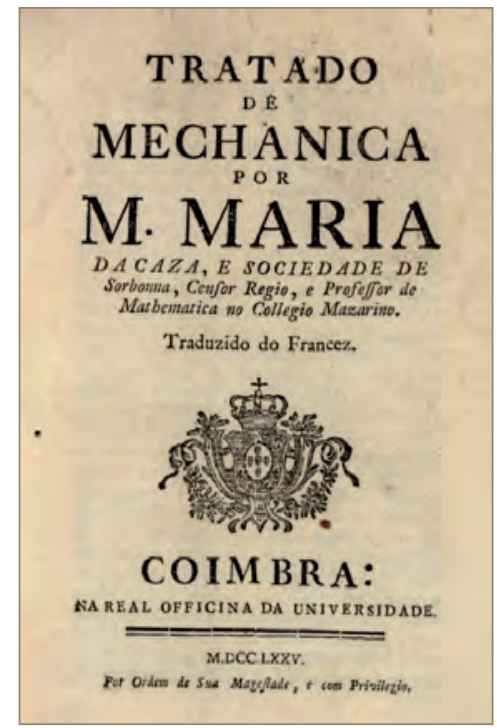

Figura 5 - Tratado de mechanica por M. Maria. - Coimbra: na Real Officina da Universidade, 1775 .

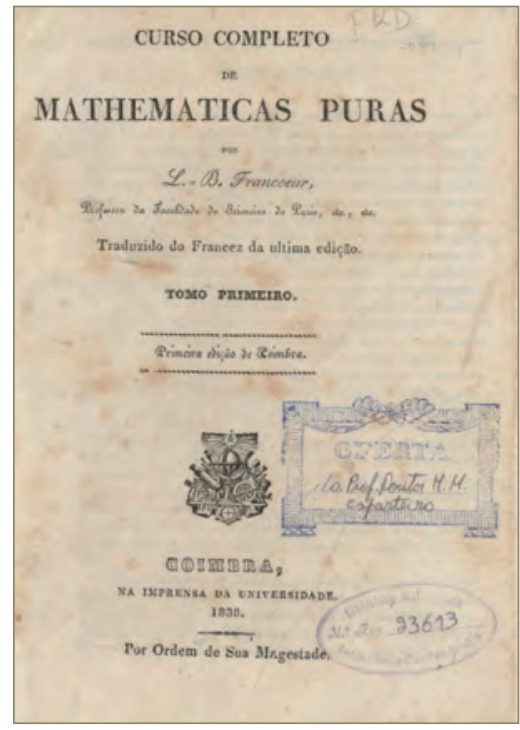

Figura 6 - Curso completo de mathematicas puras de Francoeur $-1 .^{\mathrm{a}}$ ed. de Coimbra. - Coimbra: Imprensa da Universidade, 1838.

A partir de 1838 passou a ser usado nas duas primeiras cadeiras o Curso completo de mathematicas puras de Francoeur (fig. 6). A tradução foi feita por Rodrigo Ribeiro de Sousa Pinto e Francisco de Castro Freire e saiu em 1838 e 1839. Entre 1853 e 1857 saiu uma segunda edição revista e bastante aumentada, pelos mesmos professores. Em 1871 foi feita a terceira edição, mas desta vez em volumes separados por matérias: Algebra Superior, Geometria Analytica, Calculo Differencial e Integral.

Este livro de texto é de orientação essencialmente lagrangeana; a parte relativa ao cálculo diferencial e integral começa com o desenvolvimento em série de Taylor, e a derivada é definida como o coeficiente de $h$ no desenvolvimento em série de Taylor de $\mathrm{f}(x+h)$, indicando-se que isto só não é válido "quando não houvesse tangente no ponto $(x, y)$ o que só poderia acontecer em certos casos especiaes, em que o calculo differencial appresenta com efeito resultados escuros" ${ }^{49}$. A questão da convergência das séries é tratada antes, do seguinte modo: "Sómente nos é permittido tomar a somma dos $n$

\footnotetext{
${ }^{48}$ Ibdiem, p. 45.
}

49 FRANCOUER, L. B., Curso completo de Mathematicas Puras, Primeira edição de Coimbra, Coimbra, 1839, Livro Sétimo, p. 5. 
primeiros termos de uma serie pelo valor aproximado de sua totalidade, quando esta serie for convergente i.é, quando esta somma se aproximar cada vez mais de um limite, á medida que se tomar $n$ maior; este limite é a somma de toda a serie" ${ }^{50}$. Esta definição é usada em seguida, de uma forma muito discursiva, para provar quatro critérios de convergência. Dão-se dois exemplos a título de precaução, a série harmónica e a série harmónica alternada, e para esta última é citada a página 123 do "Cours d'Analyse" de Cauchy. Nas edições seguintes esta situação mantém-se, embora os temas sejam explicados com maior clareza. Contudo na $3 .^{\text {a }}$ edição, de 1871 , aparecem quatro notas sobre séries no fim do livro: uma delas refere novamente o "Cours d'Analyse" de Cauchy a propósito do caso duvidoso do critério de convergência de séries que leva o seu nome; em duas das outras são referidos os métodos propostos por "O nosso celebre mathematico, o sr. Dr. José Anastacio da Cunha" ${ }^{51}$ para obter a série binomial e o desenvolvimento em série de $\log (1+y)$.

Em 1865 os manuais adoptados para as diferentes cadeiras eram os seguintes:

Primeiro Anno e Segundo Anno

Elementos de Euclides, Coimbra, 1862

Francoeur - Curso completo de Mathematicas Puras, Coimbra, 1853-1857, 4 vols.

Terceiro Anno

Castro Freire - Elementos de Mechanica Racional, Coimbra, 1853, 2 vol.

Sousa Pinto - Complementos da Geometria Descriptiva de Lefebure de Fourcy, Coimbra, 1853.

Quarto Anno

Sousa Pinto - Elementos de Astronomia, Coimbra, 1858.

Sousa Pinto - Cálculo das Ephemerides, Coimbra, 1849.

Monteiro da Rocha - Taboas Astronomicas, Coimbra, 1813.

Ephemerides Astronomicas para 1865, Coimbra, 1865.

E. Dubois - Traité élémentaire d'astronomie

Puissant - Géodesie et topographie

Quinto Anno

Pontécoulant - Théorie analytique du systéme du monde

Poisson - Mécanique Rationnelle

Lamé - Théorie de l'élasticité

Bresse - Méchanique appliquée

Até 1873 produziram-se poucas alterações nos textos adoptados:

\section{Primeiro Anno}

1. ${ }^{\text {C Cadeira -Geometria Analytica e Algebra Superior de Francoeur, traduzidos e aumentados por }}$ Castro Freire e Souza Pinto, Coimbra, 1871. (fig. 7).

Segundo Anno

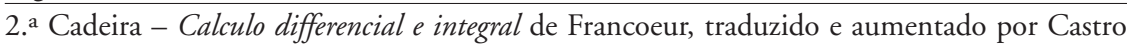
Freire e Souza Pinto. (fig. 8).

\footnotetext{
${ }^{50}$ Ibidem, Livro Sexto, p. 187.

${ }^{51}$ FRANCOUER, L. B., Algebra Superior, 3. a edição, Coimbra, 1871, Livro Sétimo, p. 298.
} 
Terceiro Anno

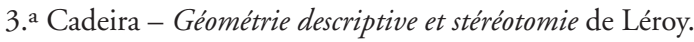

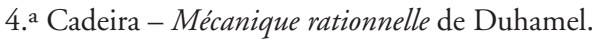

Quarto Anno

5. a Cadeira - Elementos de Astronomia de Sousa Pinto (fig. 9) e Astronomie de Dubois.

6. ${ }^{a}$ Cadeira - Géodesie et topographie de Puissant.

Quinto Anno

7. ${ }^{a}$ Cadeira - Théorie analytique du systéme du monde de Pontécoulant

8. ${ }^{a}$ Cadeira - Mécanique Rationnelle de Poisson, e Théorie de l'élasticité de Lamé

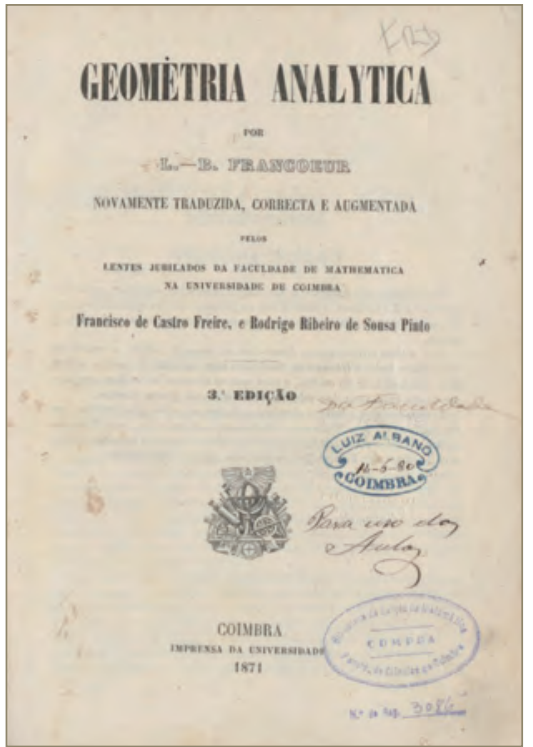

Figura 7 - Geometria analytica por L. - B. Francoeur; novamente traduzida, correcta e augmentada pelos [...] Francisco de Castro Freire e Rodrigo Ribeiro de Sousa Pinto. - 3. ${ }^{\mathrm{a}}$ ed. Coimbra: Imprensa da Universidade, 1871.

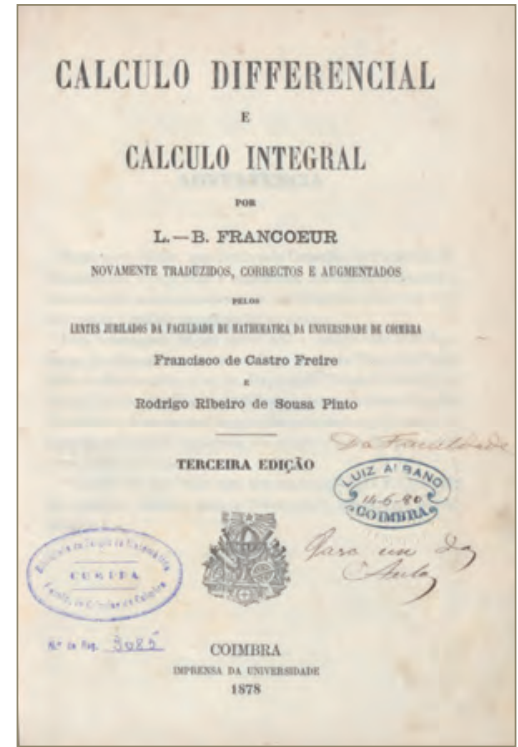

Figura 8 - Calculo differencial e calculo integral por L.-B. Francoeur; novamente traduzidos, correctos e augmentados pelos Lentes Jubilados da Faculdade de Mathematica da Universidade de Coimbra Francisco de Castro Freire e Rodrigo Ribeiro de Sousa Pinto. - 3. ${ }^{\mathrm{a}}$ ed. Coimbra: Imprensa da Universidade, 1878.

Poucas alterações foram sofrendo esta lista. O Additamento á Algebra Superior de Francoeur, de Souto Rodrigues, foi adoptado a partir de 1879/80 juntamente com os textos de Francoeur. O Traité de Mécanique Céleste de Tisserand foi adoptado durante quatro anos na $7 .{ }^{a}$ cadeira, mas, na sequência de um incidente entre os professores, regressou-se à adopção do anterior manual de Pontécoulant, 30 anos mais antigo ${ }^{52}$.

As alterações mais significativas foram a adopção do livro

$$
\text { Cours d'Analyse - Camille Jordan }
$$

${ }^{52}$ Cf. SILVA, Jaime Carvalho e, O ensino da Matemática na Universidade de Coimbra na segunda metade do séc. XIX, Actas do 2. ${ }^{\circ}$ Encontro Luso-Brasileiro de História da Matemática, São Paulo, 1997. 
em 1885, e a adopção de

\section{Curso de Analyse Infinitesimal - Gomes Teixeira}

a partir de 1889 , para a $2 .^{\mathrm{a}}$ cadeira (fig. 10).

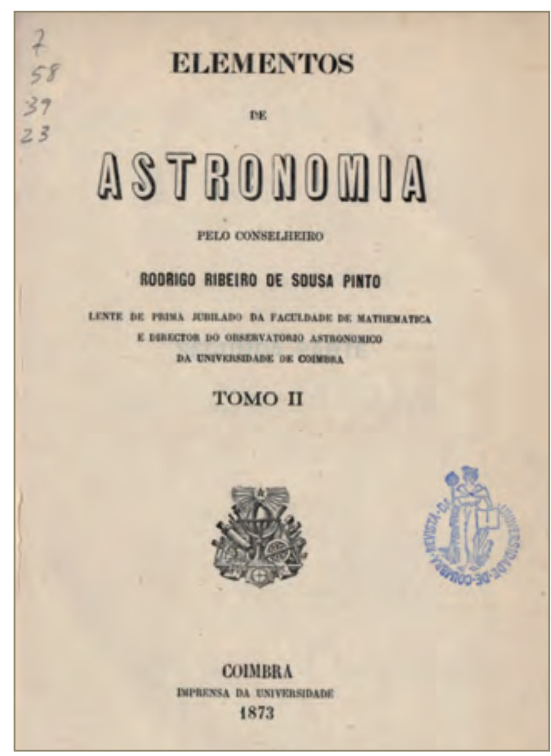

Figura 9 - Elementos de Astronomia de Rodrigo Ribeiro de Sousa Pinto. - Coimbra: Imprensa da Universidade, 1873.

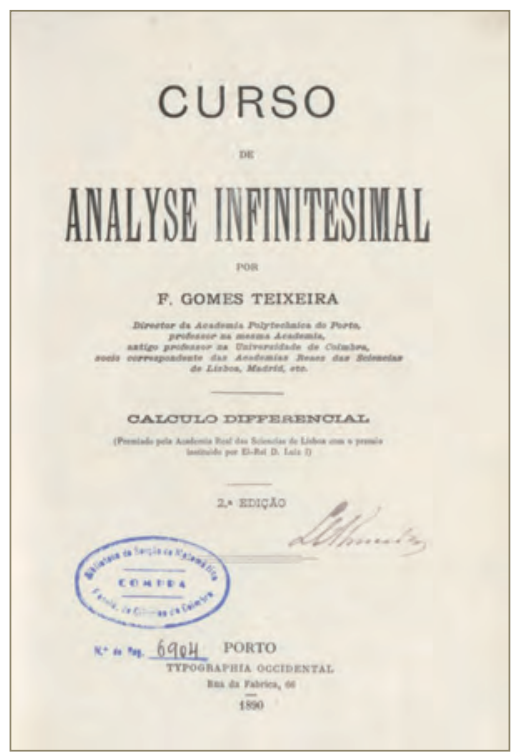

Figura 10 - Curso de analyse infinitesimal: calculo differencial por F. Gomes Teixeira. -2 a $^{\mathrm{a}}$ ed. - Porto: Typographia Occidental, 1890.

Estes manuais representam uma evolução considerável no ensino da Cálculo diferencial e integral. O manual de Camille Jourdan é um dos primeiros manuais franceses a reflectir a influência das ideias de Weierstrass, contendo um apêndice com uma das primeiras exposiçôes didácticas da teoria de conjuntos. O livro de Gomes Teixeira apresenta o que se pode considerar uma exposição moderna do Cálculo diferencial e integral. A definição de limite de uma "quantidade variável $u$ que passa por uma infinidade de valores sucessivos $u_{1}, u_{2}$, etc.," para uma "quantidade constante $A$ " é feita como "a cada valor da quantidade positiva por mais pequeno que seja, corresponde um valor $n_{1}$ tal que a desigualdade

$$
\left|\mathrm{A} u_{n}\right|<\mathrm{d}
$$

seja satisfeita por todos os valores de $n$ superiores a $u_{1}{ }^{53}$. Uma função $f$ contínua no ponto $a$ é definida como: " $f(a+b)$ tende para $f(a)$ quando $h$ tende para zero" 54 . Outras noções como a de série convergente, derivada, são apresentadas de uma forma

\footnotetext{
${ }^{53}$ TEIXEIRA, F. Gomes, Curso de Analyse Infinitesimal - Calculo differencial, 2. a edição, Porto, 1890, p. 18.

${ }^{54}$ Ibidem, p. 70.
} 
moderna. O tratado de Gomes Teixeira contém referências a inúmeros autores, de que se podem destacar Cauchy, Weierstrass e Riemann.

A falta de compêndios apropriados em língua portuguesa foi sentida durante este período de tal modo que em 1886, Luiz da Costa e Almeida apresentou uma proposta ao Conselho Superior de Instrução Pública, que não teve seguimento, de ser atribuída uma "remuneração pecuniária" aos professores encarregados da composição dos compêndios, "equivalente ao serviço de regência da cadeira". Na sua proposta, Luiz da Costa e Almeida considerava que:

“(...) é tambem absolutamente indispensável que aos alumnos se proporcionem livros proprios

(...) mas tambem sem deficiencias, como tantas se notam em alguns livros de ensino, que tornam obscuras e verdadeiramente sibyllinas muitas das suas passagens e que são a causa do tedio inveterado que o seu estudo tantas vezes desperta nos que se vêem obrigados a decifra-las (...) entre nós presentemente se não encontram livros que satisfaçam a taes condições (...)" 55 .

Embora possa parecer demasiado radical esta afirmação (certamente politizada para conseguir a aprovação da sua proposta) noutro passo do seu trabalho Luiz da Costa e Almeida afirma que a obra de Francoeur "já hoje, em parte, mal poderia satisfazer ás exigencias do ensino" o que correspondia totalmente à verdade.

\section{Os Métodos, As Temáticas}

Os Estatutos de 1772 apontam para a Matemática como uma disciplina prioritária a ser cultivada por todos na Universidade. E justificam esta distinção com o facto de a Matemática ter "uma perfeição tão indisputável entre todos os conhecimentos naturais, assim na exactidão luminosa do seu Método, como na sublime e admiravel especulação das suas doutrinas" ${ }^{6}$ e assim "illuminam superiormente os entendimentos no estudo de quaesquer outras disciplinas" ${ }^{57}$. Os Estatutos indicam claramente que a Matemática deve ser desenvolvida para bem da Universidade porque os conhecimentos matemáticos são "de grande importancia por si mesmos, e por isso dignos de servirem de termo á applicação de todos aquelles, que forem dotados do Talento necessario para nelles fazerem o devido progresso" ${ }^{58}$. Mas também indicam que a matemática se aplica em áreas importantes e que essas áreas também beneficiarão com o desenvolvimento dos estudos matemáticos, seja porque poderão aplicar o método matemático seja porque se irão obter aplicações importantes.

Este duplo objectivo aparece repetidamente depois de 1772 e ao longo de todo o século XIX. D. Francisco de Lemos retoma a temática dos Estatutos ao justificar em 1777 a criação do curso de matemática, porque esta disciplina "alem da excelencia privativa, de que goza pelas Luzes da evidencia mais pura, (...) continha em si mesma

${ }^{55}$ ALMEIDA, Luiz da Costa e, A Faculdade de Matemática da Universidade de Coimbra (1872-1892), Coimbra, 1892.

${ }^{56}$ Estatutos (1772), liv. III, Parte II, $\$ 1$.

${ }^{57}$ Ibidem, $\$ 2$.

${ }^{58}$ Ibidem, tít. II, cap. I, $₫ 1$. 
hum grande Systema de Doutrinas da maior importância; como o era o regularem-se por ellas as Epocas, e Medidas dos tempos, as Situaçoens Geographicas dos Lugares; as Demarcaçoens, e Mediçôes dos Terrenos; as Manobras, e Derrotas da Pilotagem; as Operaçoens Practicas da Campanha, e da Marinha; as Construcçoens da Architectura Naval, Civil, e Militar; as Machinas, Fabricas, Arteficios, e Aparelhos, que ajudam a fraqueza do Homem" 59 .

Em muitas das intervenções ao longo deste período encontramos a mesma temática, embora por vezes aqui e ali com algum exagero. Por exemplo, na Oração de Sapiência do ano lectivo de $1868 / 69$, pronunciada pelo Lente de Medicina Júlio Sacadura Bote, este, ao fazer um apanhado dos diversos cursos da Universidade, dá uma certa importância à matemática ao se referir às suas "verdades descobertas", mas também refere que o matemático exerce um domínio sobre a terra (e não admira que um leigo tire essa conclusão pois os títulos de 5 das 7 cadeira do curso de matemática desse ano falam de "applicaçôes ás machinas", "uso dos instrumentos opticos", "aplicações da mechanica ás construções", etc). Mas o Lente de Medicina excede-se ao afirmar: "O mathematico (...) tira das verdades descobertas illaçôes de uma utilidade practica, immediatamente applicável aos usos da vida." 60

Vamos encontrar um tom mais contido e um sentido menos utilitarista em Venâncio Rodrigues, Lente Decano e Director da Faculdade de Mathematica, na sua Oração de Sapiência de 1877: "O tempo e o espaço são qualidades necessarias para percepção dos objectos sensiveis. Os attributos que lhes são inherentes devem tambem convir aos dictos objectos; e os seus raciocinios que se podérem fazer sobre as suas propriedades são-lhes tambem applicaveis. É por este modo que se applicam a evidencia, a universalidade, e a necessidade das proposições mathematicas; e as suas applicações a todos os phenomenos do Universo.

Diz Cournot que «as mathematicas nos offerecem um caracter particular e bem notavel, que é - que as suas demonstrações se fundam unicamente em raciocinios, sem que seja necessario tomar cousa alguma emprestada á experiencia; porém que todavia seus resultados assim obtidos são susceptiveis de serem confirmados pela experiencia nos limites da exactidão que a experiencia pode dar.» D'aqui resulta que a SCIENCIA MATHEMATICA reune o caracter de SCIENCIA RACIONAL ao de SCIENCIA POSITIVA. Ella, que trata da quantidade considerada em relação ao tempo e ao espaço, é tida por Kant como o ponto de transição entre as sciencias metaphysicas e physicas, porque a Mathematica empresta seus principios áquellas; e tem relaçôes immediatas com estas." ${ }^{61}$

A preocupação com a interacção entre a Matemática e as outras Ciências esteve sempre presente. Na Oração de Sapiência que proferiu em 1887, o Lente de Matemática Rocha Peixoto afirmou: "Não podem pois as mathematicas separar-se das outras sciencias sem grave prejuizo para o ensino e progredimento d'estas". Mas acrescenta logo a seguir que é "indispensavelmente necessária" a convivência entre os matemá-

${ }^{59}$ LEMOS, Francisco de, Relação Geral do Estado da Universidade (1777), Coimbra, 1980, pp. 80-81.

${ }^{60}$ BOTE, Julio Sacadura, "Oração inaugural (de sapientia)", in Annuario da Universidade de Coimbra no anno lectivo de 1868 para 1869, Coimbra, 1868.

${ }^{61}$ RODRIGUES, Raimundo Venâncio, "Oração de Sapientia”, in Annuario da Universidade de Coimbra no anno lectivo de 1877 para 1878, Coimbra, 1877. 
ticos e os outros cientistas pois caso contrário "os mathematicos seriam absorvidos pela abstracção da analyse, pelo rigor da geometria, pela paciencia da astronomia e até pela contemplação dos céos." ${ }^{2} 2$ E enumera de seguida o que os matemáticos têm a aprender com os outros universitários - teólogos, homens de letras, juriconsultos, médicos, físicos, naturalistas - provando assim a importância da convivência de todas as áreas numa Universidade.

O curso de Matemática seguiu sempre essencialmente esta ideia de desenvolvimento da matemática, tanto tento em atenção o seu próprio desenvolvimento, como tendo em vista as aplicações e ligações a outras áreas. Os Estatutos de 1772 dão várias indicações neste sentido, mas não se limitam a indicações genéricas. Por exemplo na regulamentação dos exercícios práticos é indicado expressamente que "ajuntaráó sempre a Theorica com a Prática"63. Uma das mais preciosas indicaçôes contidas nesses Estatutos, diz contudo respeito ao enquadramento histórico e filosófico das matérias a leccionar, nos chamados "Prolegomenos Geraes das Sciencias Mathematicas". Vale a pena reproduzir aqui essas indicações:

"1 Para que as Lições do Curso Mathematico se façam com boa ordem, e com aproveitamento dos Estudantes: O Lente de Geometria, a quem pertencem as Disciplinas do Primeiro Anno, antes de entrar nas Lições proprias da sua Cadeira, lerá os Prolegomenos Geraes das Sciencias Mathematicas.

2 Nelles fará uma Introducção breve, e substanciada ao Estudo destas Sciencias: Mostrando o objecto, divisão, e prospecto geral delas: Explicando o Methodo, de que se servem; a utilidade, e excelencia delle: E fazendo hum Resumo dos sucessos principaes da sua Historia pelas Epocas mais notaveis della. Taes são: Desde a origem da Mathematica, até o Seculo de Thales, e Pythagoras: Deste até a fundação da Escola Alexandrina: Della até a Era Christã: Desta até a destruição do Imperio Grego: Della até Cartesio: E de Cartesio até o presente tempo.

3 Este Resumo será proporcionado á capacidade dos Estudantes: De sorte, que os disponha, e anime para entrarem no estudo com gosto. Por isso não entrará o Lente na relação circumstanciada dos descubrimentos, que se fizeram nas ditas Sciencias em differentes tempos, e lugares; porque não póde ser entendida, senão por quem tiver já estudado as mesmas Sciencias; e então não lhe será necessaria a voz do Mestre, para se instruir na Historia. Recommendará porém muito aos seus Discipulos, que á medida, que forem caminhando no Curso Mathematico, se vão instruindo particularmente nella: Mostrando-lhes, que a primeira cousa, que deve fazer quem se dedica a entender no progresso das Mathematicas, he instruir-se nos descubrimentos antecedentemente feitos; para não perder o tempo em descubrir segunda vez as mesmas cousas; nem trabalhar em tarefas, e emprezas já executadas." ${ }^{64}$

Indicações deste teor, embora não tão detalhadas, aparecem em todas as outras disciplinas do curso matemático. E há várias indicações de que realmente se deu alguma importância ao enquadramento histórico. Já quanto aos métodos de ensino, apesar de o Estatuto ser também muito claro e detalhado, o método expositivo tradicional deve

${ }^{62}$ PEIXOTO, Alfredo da Rocha, "Oração de Sapientia", inAnnuario da Universidade de Coimbra - Anno lectivo de 1887 a1888, Coimbra, 1888, pp. XXIV-XXVI.

${ }^{63}$ Estatutos (1772), liv. III, Parte II, tít. V, Cap. III, $₫ 2$.

${ }^{64}$ Ibidem, tít. IV, Cap. I, $\$ 1-3$. 
ter resistido às investidas de renovação. Estes são ainda assuntos pouco estudados, mas temos o testemunho de José Anastácio da Cunha, quando se envolveu em polémica pública com José Monteiro da Rocha. Diz aquele: "O meu modo de ensinar era o que a minha consciencia e intelligencia perfeitamente conformes n'esse ponto com o que os Estatutos mandam, me dictavam. Expunha o objecto das proposições, a sua connexão e dependencia; o artificio com que Euclides consegue quasi sempre unir a facilidade ao rigor geometrico; e d'este procurava dar aos estudantes o conhecimento necessario. Não me demorava em ler ou repetir litteralmente as proposiçōes que por faceis nem carecem de explicação, nem a admittem, só para poder empregar tempo sufficiente em indicar aos estudantes as verdadeiras difficuldades da lição, e facilitar-lh' as quanto as minhas tenues forças o permittiam." ${ }^{65}$

E acusava os outros lentes de não procederem deste modo, e portanto de não estarem a cumprir os Estatutos da Universidade: "O mestre repetia ou pelo livro ou de cór litteralmente as proposições da lição; e no dia seguinte cada estudante satisfazia repetindo de cór a proposição que lhe perguntavam. Nem se mostrava o uso das proposições, nem se resolviam problemas; ninguem ainda viu o lente do $1 .^{\circ}$ anno no campo ensinando as praxes que os Estatutos mandam. Debalde solicitei os instrumentos necessarios: não me consta que a Universidade tenha ainda nem uma prancheta. "66

José Anastácio da Cunha tem certamente razão neste último ponto, pois apenas na Acta da Congregação da Faculdade de Matemática de 17 de Fevereiro de 1807 aparece uma referência a uma diligência para que o material de Geometria fosse comprado:

"Os Lentes de Geometria, e Astronomia Pratica pediraõ, o p.$^{\text {ro }}$ huã Plancheta p. ${ }^{a}$ ouso dos seus Discipulos nas Liçoens praticas a q. sepropunha dar-lhes, e o seg. ${ }^{\mathrm{do}}$ alguns telescopios achromaticos p. ${ }^{a}$ o mesmp fim, atudo o q. se differio." ${ }^{67}$ Contudo, os Estatutos determinavam que "O Lente do Primeiro Anno, (...) terá o cuidado de lhes mostrar o uso prático da Geometria, e Trigonometria Plana. Para o que lhes assinará alguns dias feriados, em que Elles se devam achar em algum lugar do Campo nas vizinhanças da Cidade. Tendo feito conduzir a elle Graphometros, Pranchetas; e outros instrumentos da Geodesia; lhes mostrará a praxe das Operações sobre o terreno".

E os Estatutos dão ainda mais indicações sobre como se deve mostrar o "uso real da Geometria”. Indicaçôes semelhantes aparecem para as cadeiras dos outros anos.

As dificuldades do estudo da matemática não são iludidas e aparecem referidas várias vezes nas Orações de Sapiência. Por exemplo, na Oração de Venâncio Rodrigues já referida, aparece um incitamento à motivação dos alunos:

"Alumnos que vos dedicaes a esta sciencia, não vos desanimem as difficuldades que ella apresenta. São ellas graduaes e em harmonia com o vosso desenvolvimento intellectual. Não é mister possuir superior ingenho para ser bom mathematico: intelligencia mediana, applicação

${ }^{65}$ CUNHA, José Anastácio da, "Factos contra calumnias", in FERRAZ, M. L., RODRIGUES, J. F., SARAIVA, L. (Ed.), Anastácio da Cunha - 1744/1787 - o matemático e o poeta, INCM, Lisboa, 1990, p. 386.

${ }^{66}$ Ibidem, p. 387.

${ }^{67}$ Actas das Congregações da Faculdade de Matemática (1772-1820), Universidade de Coimbra, 1983, vol. II, p. 94 . 
não interrompida, e trabalho assiduo, compativel com as proprias forças, tanto basta para possuirdes conhecimentos de tanta utilidade para o progresso e aperfeiçoamento da Sociedade." ${ }^{68}$

Das poucas referências conhecidas se pode concluir que o ensino das disciplinas básicas de Matemática atingiu um bom nível. Por exemplo, segundo Sarmento de Beires, Francisco Gomes Teixeira, certamente o matemático português mais importante deste período, referindo-se ao professor de Álgebra do $10^{\circ}$ ano, Torres Coelho, "não esconde a influência decisiva que ele teve na sua vida, afirmando que, desde então, com todo o seu entusiasmo, se dedicou exclusivamente à Matemática." ${ }^{69}$

Também Sidónio Pais e Bruno de Cabedo são lisonjeiramente referidos por um grande matemático português da primeira metade do século XX, Mira Fernandes, como sendo excelentes professores. Vicente Gonçalves refere-se à educação de Mira Fernandes na Faculdade de Matemática da Universidade de Coimbra ${ }^{70}$ nos seguintes termos: "A matemática que lá aprendeu, porventura deficiente em extensão, foi indubitàvelmente de boa qualidade formativa. Mira Fernandes estudou Cálculo com Sidónio Pais, seguindo o curso de Gomes Teixeira: o mestre fulgia na cátedra e o texto era então dos melhores. Aprendeu Análise com José Bruno, seguindo ora Teixeira, ora Goursat, ora Picard, ao sabor de suas perfeiçôes, mas por vezes também seguindo o mestre, que não raro aqui e além a todos sobrelevava; José Bruno era inexcedível na arte de ensinar e Mira Fernandes foi seu único ouvinte em 1907-08. Cursou Mecânica com Luís da Costa, já nos seus sessenta e tantos mas ainda bem seguro na matéria em que muito havia estudado e reflectido. No quinto ano teve Mecânica Celeste com Luciano Pereira da Silva, mestre primoroso, superiormente inteligente e culto, que seguia o tratado de Tisserand sem nunca descurar a substancial introdução de Análise e Mecânica; e também nesse ano Mira Fernandes foi aluno único. Em Física Matemática, porém não terá sido tão feliz" ${ }^{71}$.

A avaliação final era inicialmente constituída por exames por anos que se foram progressivamente transformando em exames por cadeiras a partir dos finais do século XIX. Os alunos eram obrigados ainda, de acordo com o Estatuto de 1772 a realizar trabalhos escritos durante as disciplinas, tanto para exercícios relativos a problemas "Que não requerem discussão alguma, mas tão somente uma resolução breve, e elegante, ainda que sejam muito dificultosos" ${ }^{\text {" }}$, como para um assunto "que peça discussão" e sobre o qual os alunos deviam elaborar uma pequena dissertação. Esta determinação parece ter sido cumprida, pelo menos em grande parte. No espólio de Sidónio Pais ${ }^{73}$ aparecem vários trabalhos de alunos, realizados em diferentes anos lectivos, que entram nas duas categorias acima: "Achar o quarto

${ }^{68}$ RODRIGUES, Raimundo Venâncio, "Oração de Sapientia", in Annuario da Universidade de Coimbra no anno lectivo de 1877 para 1878, Coimbra, 1877.

${ }^{69}$ BEIRES, Rodrigo Sarmento de, Evocação da vida e obra do Professor Gomes Teixeira, "Anais da Faculdade de Ciências do Porto", 1950, vol. XXXV.

${ }^{70}$ Mira Fernandes fez o curso de 1904 a 1910 .

${ }^{71}$ GONÇALVES, J. Vicente, "Aureliano de Mira Fernandes, Investigador e Ensaísta”, prefácio a Obras completas de Aureliano de Mira Fernandes, 1971, vol. I, pp. V-XXI.

${ }^{72}$ Estatutos (1772), liv. III, Parte II, tít. V, Cap. IV, $\$ 4$.

${ }^{73}$ Agradeço ao Dr Armando Malheiro da Silva ter-me facultado acesso a este espólio. 
differencial total de $\mathbf{q}=f(u, v, w)$ ", "Verificar na theoria de numeros inteiros de Helmholtz a lei commutativa da addição, partindo do axioma de Grassmer", achar derivadas de funções dadas, que entram na primeira categoria, uma dissertação de 43 páginas intitulada "Integral definido simples. Critérios de integrabilidade. Funçôes integráveis" ou uma dissertação de 9 páginas intitulada "Integral intermedio geral das equações ás derivadas parciaes de $2 .^{a}$ ordem", que entram na segunda categoria de exercícios escritos.

Os exames eram normalmente baseados em pontos tirados à sorte com 24 horas de antecedência. Por exemplo, num exemplar da tradução do livro de Francoeur "Algebra Superior", encontra-se a indicação do exame realizado por um aluno (certamente da 1. ${ }^{\text {a }}$ cadeira) na seguinte forma:

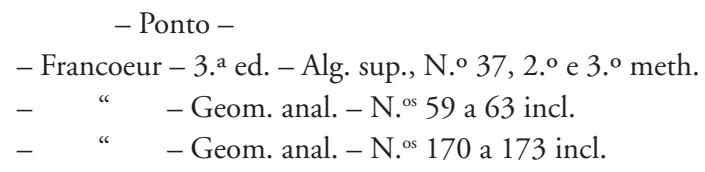

Tirado no dia 14 de Junho de 1881

Acto no dia 15

O primeiro item diz respeito à determinação de majorantes das raízes de um polinómio (o 3. ${ }^{\circ}$ método envolve a fórmula de Taylor para o polinómio). Os temas de Geometria Analítica são sobre a hipérbole e suas propriedades e sobre posições relativas de planos e rectas no espaço. No espólio de Sidónio Pais atrás referido encontra-se uma lista de pontos de exame da 1. a cadeira da Faculdade de Matemática em 1911. Eis alguns exemplos (eram 33 pontos no total):

1. Theoria dos numeros irracionais, negativos e complexos. Resolução trigonometrica das equações binomias.

2. ${ }^{\circ}$ Theoria dos numeros limites.

12. ${ }^{\circ}$ Propriedades elementares dos determinantes.

17. ${ }^{\circ}$ Funcções symetricas inteiras. Calculo das funcções symetricas simples pelo methodo de Newton. Funcções symetricas duplas e triplas. Funcçôes symetricas racionais.

22. ${ }^{\circ}$ Noção de serie. Fórmulas e Series de Taylor e de Maclaurin. Representação de funcções por estas series.

31. ${ }^{\circ}$ Theoria geral das asymptotas e das tangentes ás curvas.

Também pelas provas de avaliação se pode ver que os programas das cadeiras eram essencialmente cumpridos, e portanto pode-se ter uma ideia genérica do nível científico do curso a partir dos planos de estudo e programas conhecidos.

\section{A InVEstigação}

Tal como assinalou Luís de Albuquerque, os Estatutos de 1772 revelam uma orientação muito moderna ao indicar que "o papel da Universidade não deve ser apenas o de dotar o país com diplomas, (...) cabe-lhes também o encargo de se entregarem à 
investigação científica" 74 . E indica em abono da sua tese a criação dos "Gremios das Faculdades" cujo objectivo era "nelles se receberem todos aquelles, que, tendo acabado os seus respectivos Cursos com mais distinção, e louvor, déssem esperanças bem fundadas de poderem algum dia succeder dignamente no Magisterio (...) fazendo á contenda os estudos mais avançados, e profundos, que para isso são sempre necessarios." 75 Esta preocupação é ainda mais claramente visível no Titulo VIII que regulamenta a "Congregação da Mathematica". Aí se declara expressamente no parágrafo 4: "Em particular cuidará muito em que os descubrimentos, que se fizerem, e approvarem na Congregação Geral das Sciencias, passem logo a transfundir-se nas Lições, reduzidos a huma fórma elementar; e que os Estudantes (principalmente os Ordinarios) se criem desde o principio no espirito da mesma Congregação; para depois se fazerem habeis a entrar nella (...) e para continuarem o fio das mesmas indagaçôes. ${ }^{\eta 6}$

Não só se aponta o caminho da investigação na introdução do Livro III dos Estatutos "trabalhar no progresso, adiantamento, e perfeição das mesmas Sciencias; do mesmo modo que felizmente se tem praticado, e pratíca na Academias mais célebres da Europa; melhorando os conhecimentos adquiridos; e adquirindo outros de novo, os quaes se façam logo passar immediatamente aos Cursos respectivos" 77

Infelizmente não há notícia da criação dos "Gremios das Faculdades" ou da "Congregação Geral das Sciencias para o adiantamento, progresso e perfeição das Sciencias Naturaes "78. Na "Relação Geral do Estado da Universidade", o Reitor, D. Francisco de Lemos, explica porque não chegou a ser impressa a quarta parte do Livro Terceiro dos Estatutos onde estariam os Estatutos dessa "Congregação Geral". E insta a Rainha a promover a publicação desses Estatutos pois a "experiencia das outras Nações da Europa não nos deixa ja duvidar do Sucesso". E acrescenta vários exemplos, tal como: "A quem devem Inglaterra e França a sua Opulencia, e o flerente estado das Artes da Paz, e da Guerra, se não a Sociedade Real de Londres, e a Academia Real das Sciencias?"79

D. Francisco de Lemos lamenta-se ainda de não terem sido tomadas as "Providencias proprias, para florescerem as Sciencias, e haver bons Lentes na Universidade". O parágrafo com este título é um verdadeiro libelo em defesa da investigação científica: os Doutores deveriam ingressar no "Corpo das Faculdades" organizado à "maneira das Academias" para trabalhar em "Producçōes Literarias". E D. Francisco de Lemos indica com muito detalhe como deveria funcionar cada "Corpo das Faculdades"; na realidade trata-se de um verdadeiro seminário de investigação: "Deveriam juntar-se huma ves cada Semana na Salla da Universidade, ou em outro lugar que parecesse ao Reytor; e cada hum por seu Turno seria obrigado a ler huma Dissertação sobre alguma Materia importante da Faculdade, que fosse digna de Discussão. Depois de lida passaria a mesma Dissertaçaõ pela mão de todos os Collegas, os quaes fariam sobre ella as observaçoens, que lhes parecessem; e tudo seria revisto, e examinado pelos Lentes

${ }^{74}$ ALBUQUERQUE, Luís de, "As ciências positivas na reforma pombalina", in Em homenagem a José Anastácio da Cunha, Coimbra, 1987, pp. 19-27.

${ }^{75}$ Estatutos (1772), liv. III, Parte II, tít. I, Cap. I, $\$ 2$.

${ }^{76}$ Estatutos (1772), liv. III, Parte II, tít. VIII, Cap. I, $\$ 4$.

${ }^{77}$ Estatutos (1772), liv. III, Parte II.

${ }^{78}$ LEMOS, Francisco de, Relação Geral do Estado da Universidade (1777), Coimbra, 1980, p. 107.

${ }^{79}$ Ibidem, p. 110. 
que assistiriam ás mesmas Assembleias. As obras que fossem julgadas de merecimento seriam destinadas á Impressão." ${ }^{80}$ E D. Francisco de Lemos acrescenta que nenhum Doutor poderia aspirar a um lugar de Professor da Faculdade de Matemática sem que trabalhasse "particularmente ate fazer huma Obra, que aprezentada ao Corpo da Faculdade merecesse ser impressa entre as dos outros Academicos, sendo examinada da forma sobredita." ${ }^{81}$

Podemos ver que este espirito de algum modo teve influência através de uma referência que se pode encontrar nas Actas das Congregaçōes da Faculdade de Filosofia. Numa reunião conjunta em 1780, as Faculdades de Matemática e Filosofia concordaram que na contratação dos professores não se levasse em conta a antiguidade mas apenas os "trabalhos literarios annuaes em que se deveram exercitar e qualificarem-se perante as Congregaçôes com memorias por escrito e verbais, segundo o plano que as mesmas Congregaçōes (...) proporá a sua Magestade" ${ }^{82}$. Esta é uma prova da preocupação com a qualidade dos docentes.

Por Aviso Régio de 1787 é determinado que não tendo sido estabelecida a "Congregaçaō Geral das Faculdades Naturaes, e Filosoficas" "s3 apesar de se continuar a achar que a Congregação devia ser formada com as três Faculdades, pelo menos deviam passar à prática os princípios dos Estatutos no que a cada Faculdade respeitasse. Mas chamava a atenção para a necessidade do estabelecimento da Congregação Geral, "naõ se offerecendo, nem impossibilidade, nem dificuldade ardua, para que a Congregaçaō Geral se naõ estabeleça" ${ }^{4}$, e indicava expressamente que "Sua Magestade quer que Ellas entre Sy confiram os meyos, e os modos de Se fazer estabelecimento" ${ }^{\text {"5 }}$. Um forte incentivo ao estabelecimento da Congregação Geral, mas mais uma vez a Congregação Geral não parece ter avançado.

Uma das razōes para esta situação poderá estar na rivalidade entre as Faculdades e seus Lentes. Com efeito, os Estatutos de 1772 determinavam que tinha assento na Congregação da Faculdade de Filosofia "o Lente do Terceiro Anno do Curso Mathematico, o qual terá nesta Congregação o mesmo lugar, que teria, se fosse Lente da Faculdade" ${ }^{16}$. Esse Lente foi até 1783 José Monteiro da Rocha, Lente de Física-Matemática. Ora em 1783, Monteiro da Rocha foi nomeado Lente de Astronomia e Miguel Franzini Lente da Cadeira de Física-Matemática. Como este se encontrava ausente em Lisboa, as aulas eram dadas pelo Lente substituto, Manoel Joaquim Coelho da Costa Maya, doutorado em 1777. A Faculdade de Filosofia sempre se opôs vigorosamente a esta substituição, apesar de os Estatutos de 1772 indicarem que na Congregação teriam assento os Lentes ordinários, os Jubilados e os Substitutos. Mas em declaração de voto na reunião da Congregação de Filosofia, Domingos Vandelli, Director e Decano da Faculdade de Filosofia, declara "julgar que se lhe tem ofendido pela inobservancia do Estatuto". Só em 22 de Maio de 1786, aparece menção nas Actas da

\footnotetext{
${ }^{80}$ Ibidem, p. 163.

${ }^{81}$ Ibidem, p. 164.

${ }^{82}$ Actas das Congregaçôes da Faculdade de Filosofia (1772-1820), Universidade de Coimbra, 1978, p. 20.

${ }^{83}$ In ALMEIDA, M. Lopes d', Documentos da Reforma Pombalina, vol. II, Coimbra, 1979, pp. 137-138.

${ }^{84}$ Ibidem.

${ }^{85}$ Ibidem.

${ }^{86}$ Estatutos (1772), liv. III, Parte III, tít. VII, Cap. I, $₫ 2$.
} 
presença de Manoel Joaquim Coelho da Costa Maya na Congregação da Faculdade de Filosofia, depois de um Acórdão da Universidade datado de 27 de Janeiro de 1786. Nas Actas da Faculdade de Filosofia aprece outra menção que não abona muito ao espírito de cooperação entre as Faculdades de Matemática e Filosofia. Na reunião de 11 de Julho de 1818 refere: "Foi decidido que o lente do $3 .^{\circ}$ anno mathematico não podesse votar nas habilitaçoens dos doutores para oppositores, por ser uma coisa só privativa dos lentes da Faculdade “87. O Director e Decano da Faculdade de Filosofia era Francisco António Ribeiro de Paiva, o Lente de Matemática com assento na Congregação de Filosofia era Frei Luis Fortunato, Lente substituto, doutorado em 1807.

Os contactos directos com o estrangeiro foram escassos neste período. Entre 1801 e 1815 Manuel Pedro de Melo fez uma visita (alongada por causa das invasões napoleónicas) a França, Holanda, Bélgica e Itália como preparação para a leccionação da nova cadeira de Hidráulica. Para observar o eclipse solar total de 1860 uma comissão presidida pelo Lente de Matemática Rodrigo Sousa Pinto deslocou-se a Espanha, tendo posteriormente visitado os Observatórios de Madrid, Paris, Bruxelas e Greenwich. Fora estas deslocaçôes e ainda deslocações particulares de alguns Lentes como Luciano Pereira da Silva e Henrique de Figueiredo, não há notícia de mais contactos directos entre professores da Faculdade de Matemática e cientistas estrangeiros.

Só a partir de 1908 a Faculdade de Matemática da Universidade de Coimbra passa a dispor de verbas próprias e então atribui pela primeira vez verbas para uma "missão de estudo (...) sobre assumpto das suas cadeiras e quaisquer outros relativos à Faculdade de Mathematica" com a duração de três meses. Os primeiros professores a deslocar-se ao estrangeiro foram Luciano Pereira da Silva, Henrique de Figueiredo e Sidónio Pais. Estes últimos estiveram duas vezes em Paris (em 1909 e 1910) tendo o último visitado várias Escolas Superiores e assistido a liçōes de, por exemplo, Mme Curie, Langevin, Goursat, Appell e Picard.

Em função das citações contidas em muitos dos trabalhos realizados por Doutores pela Faculdade de Matemática, podemos dizer que, apesar dos poucos contactos, os matemáticos portugueses estavam a par da matemática produzida na época. Podemos apontar as dissertações de Henrique de Figueiredo sobre "Superfícies de Riemann" (1884), de António dos Santos Lucas "Transformaçōes de Contacto" (1897) onde são estudadas a equação de Pfaff e são referidos os métodos de Sophus Lie para a integração dos sistemas de equações diferenciais de $1 .^{a}$ ordem, de Sidónio Pais sobre a aplicação das probabilidades à "teoria dos erros das observaçōes" (1898) e de Arzilla da Fonseca sobre os quaterniōes $(1884,1885)$. Como só a partir de 1857 começaram a ser obrigatoriamente publicadas na Universidade as dissertações de doutoramento, não é possível fazer indicações semelhantes sobre teses anteriores a essa data.

Só com o lançamento do Jornal de Sciencias Matematicas e Astronomicas em 1877, por iniciativa de Francisco Gomes Teixeira, é que se desenvolveram verdadeiramente as relaçôes dos matemáticos portugueses com os seus colegas europeus, dando uma real divulgação aos trabalhos portugueses, tendo também muitos artigos de matemáticos estrangeiros sido por este meio publicados em Portugal.

Até à década de 70 as teses de doutoramento deviam versar obrigatoriamente temas de matemática aplicada. A partir dessa data encontramos temas mais variados como:

\footnotetext{
${ }^{87}$ Actas das Congregaçôes da Faculdade de Filosofia (1772-1820), Universidade de Coimbra, 1978, p. 377.
} 
"Integraes e funcções ellipticas" - 1875 - Antonio Zepherino Candido da Piedade

"Integração das equações ás derivadas parciaes de 2. ${ }^{a}$ ordem" - 1875 - Francisco Gomes Teixeira

"Principios elementares do calculo dos quaterniōes" - 1884 - Augusto d'Arzilla Fonseca

"Resolução das equações indeterminadas" - 1885 - Francisco Miranda da Costa Lobo

"Superficies de Riemann" - 1887 - Henrique Manuel de Figueiredo

"Estudo sobre funcções duplamente periodicas de primeira e segunda especie" - 1889 - José Pedro Teixeira

Também nas dissertações de concurso a um lugar de professor encontramos bastantes temas de matemática pura:

"Comparação do methodo teleologico de Wronski com os methodos de Daniel Bernoulli e Euler, para a resolução numerica das equações” - 1870 - José Joaquim Pereira Falcão

"Determinação de funcçôes ellipticas" - 1874 - João Ignacio do Patrocinio da Costa e Silva Ferreira

"Theoria dos determinantes" - 1880 - Francisco da Costa Pessoa

"Primeiras noções sobre a teoria das funcções uniformes" - 1885 - José Bruno de Cabedo e Lencastre

"Estudo de algumas equações de congruencia e indeterminadas" - 1885 - Francisco Miranda da Costa Lobo

"Curvas planas algebricas" - 1888 - Henrique Manuel de Figueiredo

Inicialmente os temas das duas liçōes que os candidatos ao lugar de professor catedrático deviam proferir eram obrigatoriamente de matemática aplicada, um de Mecânica Racional ou Física-Matemática, e um de Geodesia, Astronomia Prática ou Mecânica Celeste. Por proposta de Luiz da Costa e Almeida, apresentada ao Conselho Superior de Instrução Pública em 1885, os temas das lições do concurso passaram a ser um de Algebra, Análise, Mecânica Racional ou Física-Matemática e um de Astronomia Geodesia, ou Mecânica Celeste.

\section{IMPACTO}

Um dos principais impactos da criação da Faculdade de Matemática foi na formação de especialistas em Matemática. Para se ter uma ideia melhor da amplitude desta formação, eis o quadro dos doutoramentos em Matemática na Universidade de Coimbra durante o século XIX, agrupados por década:

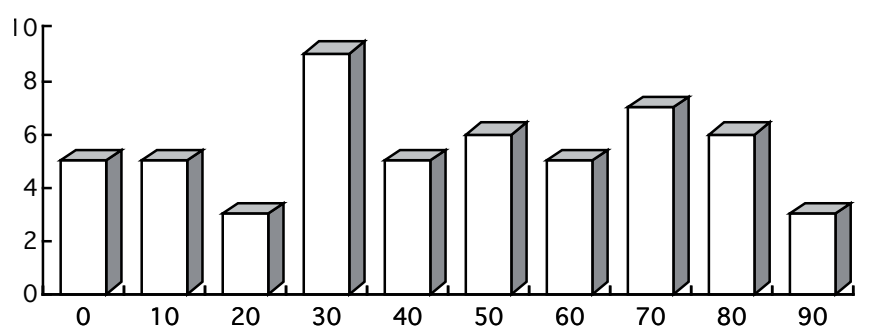


Verifica-se assim um total de 54 doutoramentos no século XIX, uma média de 5,4 doutoramentos por década, o que representa um número notável, e até consideravelmente independente das vicissitudes políticas da época.

Muitos dos doutorados ficaram professores da Faculdade de Matemática cumprindo-se o desejo dos Estatutos de que "se criem Mathematicos consumados, que possam succeder nas Cadeiras". Isto significou que, alguns anos depois da Reforma pombalina o quadro de professores já se encontrava completo ( 4 catedráticos e 2 substitutos); e depois do fim da guerra civil o quadro também se recompôs rapidamente. No início do século XIX o quadro de professores ${ }^{88}$ era

$\begin{array}{ll}\text { Catedrátricos: } & \text { Manuel José Pereira da Silva } \\ & \text { Manuel Joaquim Coelho da Costa Vasconcellos e Maia } \\ & \text { José Joaquim de Faria } \\ & \text { António José de Miranda } \\ \text { Substitutos: } & \text { António José de Araulo Santa Bárbara } \\ & \text { Fr. Joaquim de Maria Santíssima }\end{array}$

Em 1867 o quadro tinha já 8 catedráticos e 4 substitutos, e era constituído pelos seguintes professores:

$\begin{array}{ll}\text { Catedrátricos: } & \text { Abílio Afonso da Silva Monteiro } \\ & \text { Joaquim Gonçalves Mamede } \\ & \text { Raimundo Venâncio Rodrigues } \\ & \text { Rufino Guerra Osorio } \\ & \text { Jacome Luis Sarmento de Vasconcelos } \\ & \text { Florêncio Mago Barreto Feio } \\ & \text { José Teixeira Moraes Sarmento } \\ & \text { Luis Albano de Andrade Morais } \\ \text { Substitutos: } & \text { Francisco Pereira Torres Coelho } \\ & \text { António José Teixeira } \\ & \text { José Pereira da Costa Cardoso } \\ & \text { Luís da Costa e Almeida. }\end{array}$

Mas o impacto também se mede pelo número de doutorados que se tornaram professores das diversas Academias Militares e das Academias Politécnicas de Lisboa e do Porto. O impacto é ainda mais óbvio se levarmos em conta que muitos dos bacharéis em Matemática como Daniel da Silva, F. de B. Garção Stockler, Matheus Valente do Couto, Francisco Simões Margiochi, José Cordeiro Feio, J. F. Castel-Branco, Manuel Jacinto Nogueira da Gama, A. Figueiredo e Almeida, Rodrigo Ferreira da Costa, chegaram também a professores dessas escolas, pelo que é de salientar o aspecto multiplicador que teve a criação da Faculdade de Matemática em Coimbra. Observe-se que os primeiros quatro Lentes da Academia Politécnica de Lisboa ${ }^{89}$, José Cordeiro Feio, J.

${ }^{88}$ Não incluiremos em quaisquer destas estatísticas os professores de Desenho.

${ }^{89}$ Cf. SARAIVA, Luís, OLIVEIRA, A. J. Franco de (1992). "Mathematics and Mathematicians in Portugal (1800-1950)". In European Mathematics 1848-1939. 
F. Castel-Branco, A. Figueiredo e Almeida e Filipe Folque, foram todos bacharéis por Coimbra, tendo o último também o doutoramento.

No quadro seguinte resumimos as colocações dos doutorados em Matemática nas diversas instituições do País.

Destino dos doutores no período $1777-1900^{90}$

\begin{tabular}{|l|c|c|c|}
\hline & $1777-1800$ & $1800-1850$ & $1850-1900$ \\
\hline Lentes da Faculdade & $10(+2)$ & $15(+7)$ & $16(+2)$ \\
\hline Academia Politécnica do Porto & - & - & 4 \\
\hline Academia Politécnica de Lisboa & - & 4 & - \\
\hline Academias Militares & $3(+2)$ & $1(+2)$ & - \\
\hline Liceus & - & 2 & 3 \\
\hline Outros & 4 & 3 & 6 \\
\hline
\end{tabular}

Observamos que não só a Faculdade de Matemática da Universidade de Coimbra formou sem problemas os professores de que necessitou, como, além disso, forneceu pessoal docente para outras instituições que assim puderam funcionar ou iniciar o seu funcionamento com professores especialistas devidamente formados em Portugal.

\section{Conclusão}

Esta perspectiva da história da Faculdade de Matemática nos 140 anos em que funcionou autonomamente, apesar de parecer longa, é muito incompleta. Muitos elementos estão por estudar ou até por descobrir.

Apesar de se tratar de uma conclusão provisória, penso que se pode dizer que se caracterizou por uma grande qualidade em termos de ensino e uma preocupação assinalável pela investigação, mostrando uma actualização notável em relação à matemática que se ia fazendo no estrangeiro, apesar de não ter produzido muita matemática nova, devido sobretudo aos condicionalismos da época.

\footnotetext{
${ }^{90}$ Alguns professores foram primeiro Lentes da Faculdade e depois transitaram para outros lugares ou vice-versa; na contagem apenas foi considerado o último lugar ocupado. Entre parêntesis encontram-se assinalados os professores que transitaram para alguma outra instituição.
} 